\title{
Changes in Estimated Dislocation Density during Creep in Martensitic Heat-Resistant Steel
}

\author{
Manabu Tamura ${ }^{1} \&$ Fujio Abe ${ }^{2}$ \\ 1 Yokohama, Japan \\ ${ }^{2}$ National Institute for Materials Science, Tsukuba, Japan \\ Correspondence: Manabu Tamura, 6-45-2 Hinominami Konan-ku, Yokohama, 234-0055, Japan. Tel: 81-45-891- \\ 1039. E-mail: mtamura.1943@pep.ne.jp
}

\author{
Received: August 7, 2015 Accepted: August 20, 2015 Online Published: August 22, 2015 \\ doi:10.5539/jmsr.v4n4p48 URL: http://dx.doi.org/10.5539/jmsr.v4n4p48
}

\begin{abstract}
An equation for dislocation density during creep was introduced for martensitic heat-resistant steel using Orowan's equation and a thermal activation equation of Kauzmann type based on several assumptions. The dislocation density discussed here corresponds to the number of dislocations swept out of an imaginary deformable domain in an activated state and is not the so-called mobile dislocation density. The one adjustable parameter, the actual deformable domain size, was adopted in the equation as a size intermediate of the lath martensite and packet. The activation energy and volume, $Q_{\mathrm{ex}}$ and $V_{\mathrm{ex}}$, were calculated using creep curves for $9 \mathrm{Cr}-1 \mathrm{~W}$ tempered martensitic steel as a function of creep strain. The changes in the dislocation density during creep were estimated nondestructively to be roughly $10^{13} \mathrm{~m}^{-2}$ to $10^{14} \mathrm{~m}^{-2}$ using the values of $Q_{\mathrm{ex}}$ and $V_{\mathrm{ex}}$. The obtained densities were approximately comparable to the values of total dislocation density reported for directly observed ferritic/martensitic steels. It was found that the dislocation density of $9 \mathrm{Cr}-1 \mathrm{~W}$ steel initially increased and then decreased in a transition creep range, which relate to hardening and recovery, respectively. This point of inversion from hardening to recovery can be confirmed easily and nondestructively far before the time to minimum creep rate and as a matter of course the time to rupture. It is suggested that monitoring of the dislocation density can predict the unexpected decrease in long-term rupture strength in advance.
\end{abstract}

Keywords: dislocation density, dislocation velocity, creep curve, martensitic heat-resistant steel, creep equation

\section{Introduction}

It is well known that continuous recovery occurs during the creep of high-strength martensitic steel (Abe, Nakazawa, Araki \& Noda, 1992; Sawada, Maruyama, Komine, \& Nagae, 1997), except in cases of work hardening immediately after high-stress loading (Cottrell, 1997; Kimura, Sawada, Kubo, \& Kushima, 2004) or precipitation hardening within specified conditions (Abe, 2005). Variations of microstructure including that of dislocation density during creep have been studied in detail for martensitic steels (Briggs \& Pakker, 1965; Spiradek, Bauer, \& Zeiler, 1994; Ennis \& Czyrska-Filemonowicz, 2003). From the results of these studies, representative highstrength martensitic steels have been developed using sophisticated control technology for precipitation to delay recovery (Sikka, Ward, \& Thomas, 1983; Naoi et al., 1995; Abe, Tabuchi, Tsukamoto, \& Shirane, 2010). However, more than 10 years passed following the development of high-strength steels before it was clarified that the longterm rupture strengths of some of the steels tended to lower unexpectedly (Kushima, Kimura, \& Abe, 1999; Tamura, 2015). Moreover, it requires a very long time and much effort to investigate metallurgically the recovery behavior during the creep of these steels. It is thus proposed to study how to predict within a short time the decrease in long-term rupture strength by analyzing creep curves at stress levels near the $10^{5}$-h rupture strength. For example, determining the minimum creep rate (MCR) is a feasible method of predicting the unexpected drop in the long-term rupture strength, because the MCR is inversely proportional to the time to rupture within a considerable wide range of test conditions (Monkman \& Grant, 1956). However, the MCR approach is not so realistic for two reasons: first, it requires both advanced instrumentation and facilities, because the MCRs are very low, below $10^{-5} \mathrm{~h}^{-1}$ for a creep test at stress levels near the $10^{5}$-h rupture strength, and second, it still requires a long time before the MCR can be determined, because the time to the MCR for martensitic steel is approximately $25 \%$ of the time to rupture of $10^{5} \mathrm{~h}$, at least. (Abe, 2003; Abe, 2011). 
The allowable stresses for ASME Gr.122 (America Society of Mechanical Engineers) were revised because it was found that the long-term rupture strengths of the steel were considerably less the strength expected from shortterm data (Masuyama, 2007). It was also clarified for this steel that a sign of degradation can be detected even at the time to $0.5 \%$ strain, which is before the time to the MCR (Tamura, 2015). It is thus considered important to analyze creep behavior in the transition creep range in detail. However, the time to $0.5 \%$ strain cannot be used as a general index for analyzing creep curves of heat-resistant steel and the physical meaning of time to $0.5 \%$ strain is vague.

Grain boundary sliding and/or diffusional creep have not been confirmed near the test conditions for the practical uses of martensitic heat-resistant steel (Klueh, 2004), excepting for a welding joint (Elarbi, 2008) and oxidedispersion-strengthened steel (Sugino et al., 2012). Therefore, the creep behavior of martensitic steel should be described using the general variables of dislocation density and average velocity for glide motion of dislocations including climb motion. From these viewpoints, if changes in the dislocation density during creep tests can be estimated nondestructively, it is expected that a sign of an unexpected decrease in long-term rupture strength due to the early recovery of materials under development can be found easily in advance.

The flow rate of a crystal due to the glide motion of dislocations is described by Orowan's equation (Orowan, 1940):

$$
\dot{\varepsilon}=M \rho b u,
$$

where $\dot{\varepsilon}, M, b$, and $u$ are the normal flow rate under uniaxial tension, the factor of conversion from shear strain to tensile strain, the length of the Burgers vector, and the average dislocation velocity, respectively. Equation (1) is equivalent to equations derived by Taylor (1934) and Seeger (1957). $\rho$ in Equation (1) denotes the moving dislocation density. Therefore, when work hardening takes place, the number of dislocations that cross out of the crystal and consequently create a measurable strain is smaller than the number of dislocations corresponding to $\rho$ in Equation (1). In contrast, in steady-state flow, $\rho$ in Equation (1) is equal to the total number of dislocations that completely cross a single crystal on single slip planes divided by the cross section of the crystal (Cottrell, 1965).

However, in polycrystalline material, even for a steady-state flow, the number of moving dislocations within each grain (i.e., the number of dislocations crossing out of each grain) does not generally coincide with the number of dislocations that create a measurable strain of the specimen. This is because some of the dislocations crossing out of each grain are accumulated or annihilated near the grain boundaries, and therefore, the number of dislocations crossing out of grains is always larger than the number of dislocations necessary for creep strain; i.e., the number of dislocations swept out of the specimen. However, misunderstandings have arisen frequently in applying Equation 1 to flow phenomena of polycrystalline; i.e., the mobile dislocation density measured employing transmission electron microscopy (TEM) or the moving dislocation density calculated using flow curves have been discussed in relation to the observed creep rate (Ishida, Cheng, \& Dorn, 1966; Orlova, 1988; Orlova, 1992; Piccolo, Martin \& Bonneville, 2000; Hayakawa et al., 2007; Eisenlohr, Blum, \& Milicka, 2009). Hayakawa et al. (2007), for example, measured internal stresses employing a stress change test during the creep of ferritic/martensitic heatresistant steels and assuming the mobility of dislocations is proportional to the effective stress; i.e., the applied stress minus the internal stress, mobile dislocation density and average dislocation velocity were calculated as functions of creep strain. They also claimed that the calculated mobile dislocation densities were reasonable comparing with values observed employing TEM. These conclusions are valid only when the deformation behavior of polycrystalline can be presumed as that of the steady-state deformation of a single crystal.

To minimize the abovementioned uncertainties of the stress change test, how to estimate $\rho$ in Equation 1 for steady-state creep in polycrystalline is studied. The strict definition of dislocation density in polycrystalline is given below. We also assume that in steady-state creep, the dislocation motion is helped phenomenologically by a thermally activated process. The purpose of this study is not to deduce theoretically a new creep equation but rather to investigate how to detect reasonably in advance a sign for the unexpected decrease in the long-term rupture strength of martensitic steel. For this purpose, an equation for the dislocation density is introduced on the basis of several assumptions, while the meaning of each variable in the equation is made as clear as possible according to existing theory. The dislocation density can be estimated from the proposed equation using both a set of creep data and only one adjustable parameter. The proposed equation for the dislocation density in a steady state is extended to the transition and acceleration creep ranges, and thus, the changes in the dislocation density can be estimated nondestructively using a set of creep curves. The reasonableness and usefulness of the proposed equation were examined using a set of creep curves of an experimental martensitic steel, namely $9 \mathrm{Cr}-1 \mathrm{~W}$ steel. The results of the examination for the creep curves conducted in a wide range of test conditions of heat-resistant steel for practical uses will be presented elsewhere. 


\section{Introduction of Equations}

\subsection{Average Dislocation Velocity}

To calculate the dislocation density using Equation 1, it is necessary to evaluate the velocity. The average dislocation velocity in solids containing dispersive obstacles is expressed as

$$
u=\bar{\lambda} v_{\mathrm{eff}} \exp (-\Delta \bar{G} / R T),
$$

where $\bar{\lambda}$ is the mean distance that the dislocation travels and is comparable to the average obstacle spacing, $\Delta \bar{G}$ is change in the average Gibbs free energy for dispersive activation points (Schoeck, 1980), and $v_{\text {eff }}, R$, and $T$ are the effective frequency, gas constant, and absolute temperature, respectively. The value of $\Delta \bar{G}$ can be estimated, as mentioned below, using constants calculated from a set of creep curves and the temperature dependence of the shear modulus under reasonable assumptions. However, because both $\bar{\lambda}$ and $v_{\text {eff }}$ vary during creep, the expression in Equation 2 is not suitable for practical estimation of the dislocation density. We thus evaluated the use of a different expression for the dislocation velocity.

Zener (1952) expressed the rate, $\Gamma$, at which an atom moves to an adjacent lattice point as

$$
\Gamma=v_{\mathrm{D}} \exp (-\Delta g / k T),
$$

where $v_{\mathrm{D}}$ and $k$ are the Debye frequency and Boltzmann constant, respectively. $\Delta g$ is the local increase in Gibbs free energy during lattice diffusion. When single jumps perpendicular to a dislocation and towards the force occur along the dislocation line with the help of a thermally activated process, according to Equation 3, the dislocation moves one atomic distance. Such thermally activated events continue until the dislocation is trapped or annihilated. During these motions of the dislocation, assuming $v_{\mathrm{D}}$ is constant and denoting the time required for a single jump as $\tau$ and the total migration distance from the stable position of the dislocation to the trap or annihilation point as $\lambda$, we obtain the relation $\tau=1 / \Gamma=1 / \nu_{\mathrm{D}} \cdot \exp (\Delta g / k T)$ using Equation 3. Therefore, the average dislocation velocity is given by

$$
u=\lambda / \sum_{j} \tau_{j}=x_{0} v_{\mathrm{D}} /\left[\sum_{j} \exp \left(\Delta g_{j} / k T\right) /\left(\lambda / x_{0}\right)\right],
$$

where $x_{0}$ is a single jump distance. Here, $\lambda / x_{0}$ in Equation 4 is the total number of jumps during the life of the dislocation in the direction of the dislocation motion, and the term in the square brackets in Equation 4 is thus an algebraic mean of the exponential term. If we replace this term with a geometric mean, we obtain

$$
\begin{aligned}
u & =x_{0} v_{\mathrm{D}} \kappa /\left[\prod_{j} \exp \left(\Delta g_{j} / k T\right)\right]^{x_{0} / \lambda} \\
& =x_{0} v_{\mathrm{D}} \kappa \exp \left(-\sum_{j} \Delta g_{j} x_{0} / \lambda k T\right) \\
& =x_{0} v_{\mathrm{D}} \kappa \exp (-\Delta \bar{g} / k T)
\end{aligned}
$$

and

$$
\Delta \bar{g}=\sum_{j} \Delta g_{j} /\left(\lambda / x_{0}\right)
$$

where $\Delta \bar{g}$ denotes an algebraic mean of the change in the Gibbs free energy for each jump of the dislocation throughout its life. $\kappa$ is the ratio of the geometric mean to the algebraic mean and the geometric mean is equal to or smaller than the algebraic mean $(\kappa \leq 1)$. We can assume that $\kappa \approx 1$ in practice, when $\Delta g_{j}$ is as large as that for self-diffusion or so long as $\Delta g_{j}$ does not become excessively small during the travel of the dislocation. These situations were sufficiently evidenced by the systematic work of Sherby, Orr, \& Dorn (1953) on the creep of pure metals. Equation 5 does not imply that a dislocation can move without any resistance to the next obstacle after overcoming the first obstacle with the help of a thermal activation process. Apart from thermally overcoming dispersive obstacles, the dislocation may overcome resistance to the same level as lattice diffusion over its lifetime, like viscous flow. Meanwhile, Equation 5 indicates that the dislocation velocity can be estimated when $\Delta \bar{g}$ can be evaluated adequately, because the pre-factor of Equation 5 is insensitive to variations in microstructure during creep. Comparing Equations 2 and 5 and assuming $x_{0}=b$, we obtain

$$
\bar{\lambda} v_{\text {eff }}=b v_{\mathrm{D}} \kappa \text {. }
$$

On the left side of Equation 7, $\bar{\lambda}$ and $v_{\text {eff }}$ depend on the dispersion spacing of the obstacles and the strength of the elastic interaction between obstacles and dislocations, respectively. However, the right side of Equation 7 becomes $b v_{\mathrm{D}} \kappa=2.5 \mathrm{kms}^{-1}$ if we assume that $b=2.5 \times 10^{-10} \mathrm{~m}, \kappa=1$, and $v_{\mathrm{D}}=10^{13} \mathrm{~s}^{-1}$. The obtained value is approximately equivalent to the velocity of sound in steel and is a constant that is independent of the microstructure. Schoeck (1980) estimated that $v_{\mathrm{eff}} / v_{\mathrm{D}}$ ranges from 1 for strong obstacles to 0.001 for weak obstacles. This leads to $\bar{\lambda}$ in Equation 7 ranging from 0.25 to $250 \mathrm{~nm}$. These values are reasonable spacings 
among obstacles for dispersion strengthening materials. Equation 7 shows that the variations in $\bar{\lambda}$ and $v_{\text {eff }}$ during creep cancel each other out and, as a result, the product of $\bar{\lambda} v_{\text {eff }}$ becomes independent of the changes in microstructure during creep.

Although an estimation of the traveling distance of the moving dislocations can be omitted, the physical meaning of the traveling distance is included in $\Delta g_{j}$ in Equation 7; i.e., the activation volume is a component of $\Delta g_{j}$ because the activation volume is the product of the area swept by the dislocations and the length of the Burgers vector. Additionally, the strength of interaction between the dislocations and the obstacles is represented by the increase in internal energy; i.e., the internal energy is also a component of $\Delta g_{j}$. It is thus not unusual to be able to image continuous thermally activated processes like lattice diffusion as a dislocation motion. Although Equation 5 is obtained from premises and has not been experimentally validated, if Equation 5 is assumed to be reasonable, we can discuss the variations in the dislocation density during creep much more thoroughly.

\subsection{Rate Equation for Creep and the Activation Volume}

The time (Andrade, 1910; Cottrell \& Aytekin, 1947; Sully, 1949; Prager, 1995), temperature (Dickenson, 1922; Sherby et al., 1953), and stress (Norton, 1929) dependences of the creep of metals at high temperatures have long been systematically studied. In contrast with these phenomenological approaches for creep, Eyring (1936) developed absolute reaction rate theory for viscous flow on the basis of thermodynamics. Employing Eyring's theory, Kauzmann (1941) presented the creep rate as a function of temperature and stress for crystalline solids:

$$
\dot{\varepsilon}=\dot{\varepsilon}_{0} \exp (-\Delta f / k T) \sinh (v \sigma / k T),
$$

where $\Delta f$ is the change in the Helmholtz free energy in the activated state when there is shear deformation of one atomic distance. $\dot{\varepsilon}_{0}$ and $\sigma$ are a constant and the applied normal tensile stress, respectively, and $v$ is a constant (hereafter referred to as the activation volume following Seeger (1957) and Schoeck (1957)). In a high stress range, $\sinh (x) \approx 0.5 \exp (x)$ for $x>1$ and Equation 8 indicates that the activation energy for creep deformation is reduced from $\Delta f$ to $\Delta f-\sigma v$ by applying external stress.

According to Kauzmann's shear model, $v \approx b^{3}$ is obtained assuming one atomic distance is $b$. Kauzmann (1941) also reported that $v \approx 30-3300 b^{3}$ according to creep data for 16 kinds of lead, tin, zinc, brass, and steel, though the values of $v$ depended on the type of alloy and were large for higher temperatures and/or stresses; i.e., the observed values of $v$ are much larger than the value for the theoretical model. Dushman, Dunbar, \& Huthsteiner (1944) confirmed similar results that $v \approx 35-650 b^{3}$ for constantan, Al, Al-Mg alloy, Ni alloy, Pt, and Ag. Kauzmann (1941) considered that the difference between the observed values of $v$ and the modeled value could be explained by the motion of a dislocation. Many researchers have studied creep rate equations of Kauzmann's type theoretically using different dislocation models. According to these works, the constant or activation volume, $v$, is expressed as

$$
v=M b \Delta x \ell_{\mathrm{s}},
$$

for any model studied (reviewed by Schoeck, 1957), where $\Delta x$ is the activation distance required to thermally overcome the obstacles and $\Delta x \approx 0.5 b$ is assumed, and $\ell_{\mathrm{s}}$ is the length of a dislocation segment. Substituting $v \approx 30-3300 b^{3}$ reported by Kauzmann (1941) into Equation 9 and assuming $M=0.5$, we obtain $\ell_{\mathrm{s}} \approx 60-$ $6600 \mathrm{~b}$. The values obtained may be reasonable as compared with values based on metallurgical common sense. Equations 8 and 9 are obtained from the following considerations (Kauzmann, 1941; Gibbs, 1964; Schoeck, 1965; Gibbs, 1965; Gibbs, 1969). When a dislocation overcomes an obstacle thermally and under the help of applied stress, the thermal potential of a specimen becomes a maximum in an imaginary activated state, at distance $\Delta x$ from the normal position of the dislocation under free stress. At this point, the activation potential, $\Delta f$, is reduced by $v \sigma$, which corresponds to the work imparted by the specimen to a loading system. Afterward, the dislocation can glide out of the specimen without any additional energy, which generates both plastic strain and a strain rate. However, this is only valid when a single dislocation segment overcomes dispersive obstacles of the same quality and then glides in a single slip system operating within a single crystal or, in the case of the motion of many dislocations, there is no elastic interaction among these dislocations.

In contrast, within polycrystalline material, even if a dislocation is generated in a grain and the dislocation overcomes the obstacles via thermally activated processes and then arrives at the grain boundary, the dislocation may be trapped, absorbed or annihilated near the grain boundary. Therefore, to generate the same plastic strain in polycrystalline material as that for the single crystal, many more dislocations should be activated in polycrystalline material. Some of the dislocations pass through the grain boundary or activate dislocation sources nearby the boundary in an adjacent grain, and these dislocations in the adjacent grain glide further and generate plastic strain in the grain. Repeating these processes, finally, dislocations that have arrived at the surface of a specimen generate 
detectable plastic deformation. That is to say, it is difficult in the case of polycrystalline material having practical uses to specify or model a predominant obstacle for a dislocation to generate plastic deformation and to define the activation process, because the microstructures including grain boundaries, dislocations, and precipitates are highly complex. These situations discourage us from applying Equation 8 to the creep rate of martensitic steel for practical uses. Therefore, since Norton (1929), the so-called power law, where the logarithm of the creep rate or the time to rupture is described as a function of the logarithm of the applied stress, in most cases has been used in arranging time to rupture of heat-resistant materials for practical uses. However, it is also well known that the time to rupture is inversely proportional to the minimum creep rate (Mankman \& Grant, 1956). Therefore, it has been also well confirmed experimentally that a modified equation of an exponential type for Equation 8 remains very useful to this day in arranging long-term rupture data for wide ranges of temperature and stress of many kinds of heat-resistant steels for actual use (Tamura, Esaka, \& Shinozuka, 1999). The literature has confirmed linear relationships between $v \sigma / k T$ in Equation 8 and the logarithm of the time to rupture even for low stresses of about $30 \mathrm{MPa}$ for steels and $1 \mathrm{MPa}$ for Pb-Sn eutectic solder alloy (Tamura, Esaka, \& Shinozuka, 1999; Tamura, Esaka, \& Shinozuka, 2003). Moreover, Kanter has already pointed out in a written comment in a Larson-Miller paper (Larson \& Miller, 1952) that the fitness of the semi-logarithmic relation between the stress and time to rupture was superior to that of the power law plot. When we consider creep phenomena as a whole process, these findings suggest that Equation 8 may be applicable to polycrystalline material and that it may be possible to image an imaginary activation process that represents a creep phenomenon of polycrystalline material. The following scenario is developed under this hypothesis, though an activation process is not specified.

\subsection{Relation among the Activation Distance and other Parameters}

Experimentally, the values of $v$ of polycrystalline materials calculated using Equation 8 differ from those of single crystals for the same metals. Kauzmann (1941) reported that $v \approx 195 b^{3}$ for polycrystalline tin at room temperature is smaller than $v \approx 2903 b^{3}$ for a single crystal by an order of magnitude or more. Cottrell \& Aytekin (1950) reported that $v \approx 18 b^{3}$ for polycrystalline zinc at $120^{\circ} \mathrm{C}$ is smaller than $v \approx 830 b^{3}$ for a single crystal by approximately two orders of magnitude. If we apply this phenomenon that the activation volume of a polycrystalline material is smaller than that of a single crystal to Equation 9, we can guess the area swept out by dislocation motion in an activation process in polycrystalline is smaller than that in a single crystal, $\Delta x \ell_{s}$. However, the activation distance for an imaginary activated process in polycrystalline is unknown and we thus symbolize the activation distance for polycrystalline material as $X_{\mathrm{a}}$. Equation 9 is formally rewritten as

$$
v \approx M b X_{\mathrm{a}} \ell_{\mathrm{s}} \text {. }
$$

The value of $X_{\mathrm{a}}$ should correlate with creep strain in an imaginary activation process in polycrystalline, because $X_{\mathrm{a}}$ is a variable of the term $\sigma v$ and $\sigma v$ is the work done by the specimen on the loading system, as explained below; i.e., $X_{\mathrm{a}}$ should correlate with the experimentally obtained activation volume.

First, we define an imaginary domain, $\mathrm{D}_{\mathrm{m}}$, the size of which is $d_{\mathrm{m}} \times d_{\mathrm{m}}\left(d_{\mathrm{m}}<d_{0}\right)$ in an activated process, where $d_{0}$ is the width of the specimen. Such a domain is partitioned by boundaries with the adjacent domains and distributed uniformly in the specimen. When $n_{0}$ dislocations are swept out of the domain, the dislocation density for swept-out dislocations can be defined as

$$
\rho=n_{0} / d_{\mathrm{m}}^{2} \text {. }
$$

The activated tensile strain, $\varepsilon_{\mathrm{a}}$, generated by these dislocations is defined as

$$
\varepsilon_{\mathrm{a}}=M b n_{0} / L_{0} \cdot L_{0} / d_{\mathrm{m}}=M b \rho d_{\mathrm{m}},
$$

where $L_{0}$ is the length of the specimen and is usually larger than $d_{0}$, though $\varepsilon_{\mathrm{a}}$ is independent of $L_{0}$. New relations similar to Equations 11 and 12 are also obtained in a real space as

$$
\rho_{\text {inc }}=N_{0} / d_{0} L_{0}
$$

And

$$
\varepsilon_{\text {inc }}=M b N_{0} / L_{0}=M b \rho_{\text {inc }} d_{0} .
$$

Here, $\varepsilon_{\text {inc }}$ denotes not the total creep strain at an instant in time, $\varepsilon$, but the strain increment with which we calculate the creep rate, $\varepsilon_{\text {inc }} / \Delta t$, where $\Delta t$ is time increment and we can select a value of either $\varepsilon_{\text {inc }}$ or $\Delta t$ arbitrarily, and $N_{0}$ is the actual number of dislocations swept out of the specimen during $\varepsilon_{\text {inc }}$ or $\Delta t$ and $\rho_{\text {inc }}$ is thus the minimum dislocation density for the plastic deformation of $\varepsilon_{\text {inc }}$. Grain boundaries are sink sites for dislocations, and therefore,

$$
n_{0} \cdot L_{0} / d_{\mathrm{m}}>N_{0}
$$


From Equations $11,12,13,14$, and 15 and the definition of $d_{0}>d_{\mathrm{m}}$, we obtain

and, therefore,

$$
\rho=n_{0} / d_{\mathrm{m}}{ }^{2} \cdot d_{0} L_{0} / N_{0} \cdot \rho_{\text {inc }}=d_{0} / d_{\mathrm{m}} \cdot\left(n_{0} \cdot L_{0} / d_{\mathrm{m}}\right) / N_{0} \cdot \rho_{\text {inc }}>\rho_{\text {inc }},
$$

$$
\varepsilon_{\mathrm{a}}=\rho / \rho_{\text {inc }} \cdot d_{\mathrm{m}} / d_{0} \cdot \varepsilon_{\text {inc }}=\left(n_{0} \cdot L_{0} / d_{\mathrm{m}}\right) / N_{0} \cdot \varepsilon_{\text {inc }}>\varepsilon_{\text {inc }} .
$$

We cannot specify rigidly the relation of Equations 16 and 17 and we therefore assume

Using Equations 11, 13, and 18 we have

$$
\alpha \equiv \varepsilon_{\text {inc }} / \varepsilon_{\mathrm{a}}=N_{0} /\left(n_{0} \cdot L_{0} / d_{\mathrm{m}}\right), \quad 0<\alpha<1 .
$$

From Equations 12 and 18, we obtain

$$
\beta \equiv \rho_{\text {inc }} / \rho=\alpha d_{\mathrm{m}} / d_{0}, \quad 0<\beta<1 .
$$

$$
\varepsilon_{\text {inc }}=\operatorname{Mb\rho }\left(\alpha d_{\mathrm{m}}\right)^{2} / \alpha d_{\mathrm{m}}=M b \rho\left(\alpha d_{\mathrm{m}}\right) .
$$

This relation indicates that when the number of dislocations corresponding to density $\rho$ is swept out of a domain having dimensions $\alpha d_{\mathrm{m}} \times \alpha d_{\mathrm{m}}$, strain of $\varepsilon_{\text {inc }}$ is generated in the domain. Such domains fill the specimen, and thus, the actual creep strain of $\varepsilon_{\mathrm{inc}}$ is observed. Therefore, the domain of $\alpha d_{\mathrm{m}} \times \alpha d_{\mathrm{m}}$, which is smaller than the imaginary domain, $D_{\mathrm{m}}$, should be an existing domain; e.g., lath martensite, a block, or a packet. In polycrystalline material, multiple-slip systems are always activated owing to the constraint from neighboring grains, and the value of $M$ in Equation 20 should thus be modified from its original meaning. However, neglecting this modification and assuming $\alpha d_{\mathrm{m}} \approx 1 \mu \mathrm{m}$, we obtain $\rho \approx 2 \times 10^{13} \mathrm{~m}^{-2}$ for $\varepsilon_{\mathrm{inc}}=0.25 \%$. This means that the dislocation density can be calculated by measuring the values of $\alpha d_{\mathrm{m}}$ for a given $\varepsilon_{\text {inc }}$ through investigating microstructures via interruption of the creep test. However, our purpose is to estimate the dislocation density as a function of creep strain using creep curves nondestructively and not to evaluate the value of $\alpha d_{\mathrm{m}}$ at a certain strain or time.

Incidentally, a specimen in an activated state elongates by $\Delta L$ under a tensile load, $P$, and the specimen does work on the loading system equal to $P \Delta L$ (Esherby, 1956; Mura \& Mori, 1976) and this work is expressed by $\sigma v$ in Equation 8 . The work done by the specimen having a cross section $v_{\mathrm{m}} / L_{0}$, where $v_{\mathrm{m}}$ is the molar volume, is given by

$$
P \Delta L=v_{\mathrm{m}} \sigma \Delta L / L_{0}=\varepsilon_{\mathrm{a}} v_{\mathrm{m}} \sigma=\sigma V,
$$

where $V$ is the activation volume having dimensions of units per mole. Finally, from Equations 18 and 21, we obtain

$$
V=\varepsilon_{\mathrm{a}} v_{\mathrm{m}}=v_{\mathrm{m}} \varepsilon_{\mathrm{inc}} / \alpha .
$$

Equation 22 can be rewritten using Equation 20 and the definition of dislocation density as

$$
V=M b \rho v_{\mathrm{m}}\left(\alpha d_{\mathrm{m}}\right) / \alpha=M b n_{0} \ell_{\mathrm{s}}\left(\alpha d_{\mathrm{m}}\right) / \alpha .
$$

Comparing Equation 23 with Equation 10, we obtain

$$
X_{\mathrm{a}}=\left(\alpha d_{\mathrm{m}}\right) / \alpha .
$$

If we assume $\alpha=\beta$ (i.e., $\rho_{\text {inc }} / \rho=N_{0} /\left(n_{0} L_{0} / d_{\mathrm{m}}\right)$ ), from Equations 18, 19, and $24, d_{\mathrm{m}}=d_{0}$ (i.e., $X_{\mathrm{a}}=d_{0}$ ). In contrast, if $\alpha=1$, Equation 24 indicates $X_{\mathrm{a}}=\alpha d_{\mathrm{m}}$, which may be comparable to the actual grain size, such as a packet. Therefore, the activation distance in polycrystalline material, $X_{a}$, is considered to range from approximately the size of one grain to the size of the specimen, which is very wide compared with that for a model of a single jump of a dislocation in a single crystal, $\Delta x$, shown in Equation 9. Summarizing this section, it is pointed out that the parameters $\alpha, \beta, \varepsilon_{\mathrm{a}}, X_{\mathrm{a}}, \rho, \rho_{\mathrm{inc}}, d_{\mathrm{m}}, \alpha d_{\mathrm{m}}$, and $V$ are correlated with each other through Equations $10,12,13,18,19,20,22,23$, and 24 though $\varepsilon_{\text {inc }}$ is an arbitrary or independent variable.

\subsection{Experimental Determination of Dislocation Density}

Schoeck expressed the change in the Gibbs free energy for an activation process of a dislocation as

$$
\Delta g=\Delta g^{\prime}-M\left(\sigma-\sigma_{\mathrm{i}}\right) \ell_{\mathrm{s}} b \Delta x,
$$

where $\Delta g^{\prime}$ is the change in the Gibbs free energy due to the position change of $\Delta x$ between the normal and activated states, and $\ell_{\mathrm{s}}$ is the length of a dislocation segment. $\Delta g$ in Equation 25 has the same meaning as that in Equations 5 and 6. $\sigma-\sigma_{\mathrm{i}}$ in Equation 25 denotes the effective stress acting on the dislocation and the dislocation jumps in the direction of the applied stress when $\sigma>\sigma_{i}$. Equations equivalent to Equation 25 for the activated motion of a dislocation were also reported by Seeger (1957) and Gibbs (1964, 1965, and 1969). However, the internal stress, $\sigma_{i}$, indicated in Equation 25 is not equal to the average internal stress obtained in a stress change test, because internal stress changes every moment three dimensionally (Yoshinaga, 1977). Therefore, by dividing 
the second term on the right side of Equation 25, using the average variables with dimensions of per-unit-mole, and referring to Equations 9 and 10, the changes in the Gibbs free energy due to the imaginary activation motion in polycrystalline can be rewritten formally, as the well-known relation

$$
\Delta G=\Delta H-\Delta S T=\Delta U-\Delta S T-\sigma V,
$$

and combining the approximation of Equation 8 for high stresses and Equations 1 and 5, we obtain

$$
\dot{\varepsilon}=M \rho b x_{0} v_{\mathrm{D}} \kappa \exp (-\Delta G / R T),
$$

where $\Delta G, \Delta H, \Delta S, \Delta U$, and $V$ are the change in the Gibbs free energy for the motion of all swept-out dislocations for creep, the change in the enthalpy, the change in the entropy, the increase in the internal elastic energy, and the activation volume, respectively. The energy barrier for the swept-out dislocations to overcome via thermally activated processes is expressed as

$$
\Delta H=\Delta U-\sigma V
$$

Finally, Equation 27 can be rewritten as

$$
\dot{\varepsilon}=\dot{a}_{0} \exp (\Delta S / R) \exp (-(Q-\sigma V) / R T)
$$

and

$$
\dot{a}_{0}=M \rho b^{2} v_{\mathrm{D}} \kappa .
$$

$Q$ is the increase in internal elastic energy; i.e., $Q=\Delta U$. Most previous reports on creep only discuss $Q$ and we therefore use $Q$ and refer to $Q$ as the apparent activation energy. Equations 29 and 30 appear like popularly used relations. However, in Equation 29 for the creep of polycrystalline material, it is necessary to note the meaning of the activation volume given in Equation 23.

$\Delta H$ and $V$ values correlate with the experimentally determined $\Delta H_{\mathrm{ex}}, V_{\mathrm{ex}}$, and $Q_{\mathrm{ex}}$ values as given in

$$
\begin{gathered}
\Delta H=\Delta H_{\mathrm{ex}}-R T^{2}\left(\partial \ln \dot{a}_{0} / \partial T\right)_{\sigma}, \\
\Delta H_{\mathrm{ex}}=Q_{\mathrm{ex}}-V_{\mathrm{ex}} \sigma=R T^{2}(\partial \ln \dot{\varepsilon} / \partial T)_{\sigma}, \\
V=V_{\mathrm{ex}}-R T\left(\partial \ln \dot{a}_{0} / \partial \sigma\right)_{T},
\end{gathered}
$$

And

$$
V_{\mathrm{ex}}=R T[\partial \ln \dot{\varepsilon} / \partial \sigma]_{T},
$$

where the subscript "ex" indicates experimentally obtained values. The value of $Q_{\mathrm{ex}}$ can be easily calculated using Equations 32 and 34.

Equation 29 can be rewritten using Equations 28, 30, 31, 32, 33, and 34:

$$
T\left(-\log \dot{\varepsilon}+C_{\mathrm{ex}}\right)=\left(Q_{\mathrm{ex}}-V_{\mathrm{ex}} \sigma\right) / 2.3 R,
$$

where

$$
C_{\mathrm{ex}}=\Delta S / 2.3 R+\log \left(M \rho b^{2} v_{\mathrm{D}} \kappa\right)+T / 2.3 \cdot(\partial \ln \rho / \partial \ln T)_{\sigma} .
$$

The left side of Equation 35 is the famous Larson-Miller parameter (Larson \& Miller, 1952) and the LarsonMiller constant, $C_{\mathrm{ex}}$, is not a simple adjustable parameter for arranging creep data. However, it has a clear physical meaning, as shown by Equation 36 (Tamura, Abe, Shiba, Sakasegawa, \& Tanigawa, 2013).

To calculate the dislocation density, a formulation of the entropy change is necessary. Zener (1951) suggested that changes in entropy for diffusion can be calculated using the activation enthalpy and the temperature dependence of the shear modulus. Using Zener's idea, Schoeck $(1965 ; 1980)$ derived an expression for the change in Gibbs free energy during plastic deformation based on reasonable assumptions such as $\dot{a}_{0}=\dot{a}_{0}(\sigma / \mu, T)$ :

$$
\Delta G=Q_{\mathrm{ex}} / \phi+V_{\mathrm{ex}} \sigma(1-\phi) / \phi+\gamma,
$$

where

$$
\gamma=R T^{2} / \phi \cdot\left(\partial \ln \dot{a}_{0} / \partial T\right)_{\mu} \quad \text { and } \quad \phi=1-\partial \ln \mu / \partial \ln T .
$$

Combining Equations 5 and 37, we obtain

$$
u=b v_{\mathrm{D}} \kappa \exp \left[-\left(Q_{\mathrm{ex}} / \phi+V_{\mathrm{ex}} \sigma(1-\phi) / \phi+\gamma\right) / R T\right] .
$$

However, Equation 39 still contains the unknown variable $\gamma \cdot \gamma$ in Equation 38 cannot be solved until the function $\dot{a}_{0}$ is clarified. Therefore, we treat $\gamma$ as an adjustable parameter on the basis of the metallurgical considerations mentioned below.

If an appropriate $\gamma$ value is selected, the dislocation density can be easily calculated from Equations 1 and 39: 


$$
\rho=\dot{\varepsilon} / M b^{2} v_{\mathrm{D}} \kappa \cdot \exp \left[\left(Q_{\mathrm{ex}} / \phi+V_{\mathrm{ex}} \sigma(1-\phi) / \phi+\gamma\right) / R T\right] .
$$

The dislocation density in Equation 40 is based on Equation 1, which was introduced using a single crystal and single slip system model. However, in Equation 40, all dislocations swept out of the imaginary deformable domain, $\mathrm{D}_{\mathrm{m}}$, surrounded by boundaries in polycrystalline material are counted as dislocations. Therefore, the dislocations pinned within the domains are not considered. These retained dislocations in the domains contribute to an increase in the internal energy, $Q$.

\subsection{Determination of $\gamma$}

Combining Equations 23 and 40, we obtain

$$
d_{\mathrm{m}}=V b v_{\mathrm{D}} \kappa / \dot{\varepsilon} v_{\mathrm{m}} \cdot \exp \left[-\left(Q_{\mathrm{ex}} / \phi+V_{\mathrm{ex}} \sigma(1-\phi) / \phi+\gamma\right) / R T\right] .
$$

From Equations 22 and 41, the actual domain size is obtained as

$$
\alpha d_{\mathrm{m}}=\varepsilon_{\mathrm{inc}} b v_{\mathrm{D}} \kappa / \dot{\varepsilon} \cdot \exp \left[-\left(Q_{\mathrm{ex}} / \phi+V_{\mathrm{ex}} \sigma(1-\phi) / \phi+\gamma\right) / R T\right] .
$$

Given that the value of the strain increment, $\varepsilon_{\text {inc }}$, can be selected arbitrarily and $\alpha d_{\mathrm{m}}$ is proportional to the strain increment as seen in Equation 20, the actual domain size may seem to be much smaller when $\varepsilon_{\text {inc }}$ approaches zero. However, Equation 42 indicates that an adequate value of $\gamma$ should be determined to obtain a reasonable $\alpha d_{\mathrm{m}}$ value. Therefore, we denote by $d_{\mathrm{u}}$ and $d_{1}$ the upper and lower limits of $\alpha d_{\mathrm{m}}$, respectively:

$$
d_{1} \leq \alpha d_{\mathrm{m}} \leq d_{\mathrm{u}} .
$$

In the case of a typical martensitic heat-resistant steel, the upper limit for $\alpha d_{\mathrm{m}}$ is the packet size $d_{\mathrm{u}} \sim 5 \mu \mathrm{m}$, where the packet is a minimum unit surrounded by large-angle boundaries in martensitic steel. Schäublin, Spätig, \& Victoria (1998) observed the dislocation structure of a crept specimen employing TEM and showed that only screw dislocations were present within lath martensite in $8 \mathrm{Cr}-2 \mathrm{~W}$ steel. This suggests that retained dislocations with an edge character were absorbed in the lath boundaries. It is therefore reasonable for martensitic steel to have a lower $\alpha d_{\mathrm{m}}$ limit, which is a lath martensite width of $d_{1} \sim 0.2 \mu \mathrm{m}$. Therefore, the value for $\gamma$ can be determined by selecting adequate $\alpha d_{\mathrm{m}}$ values that satisfy Equation 43 .

\section{Experimental Verification of Dislocation Density}

\subsection{Material and Creep Test}

$9 \mathrm{Cr}-1 \mathrm{~W}$ martensitic steel was selected to experimentally verify Equations 39 and 40, because variations in microstructure are simple and a set of long-term digital creep data is available for the steel. The steel was vacuum melted, forged, and rolled, and then quenched and tempered. The detailed preparation and test method as well as variations in the microstructure have been reported by Abe (2003). The creep tests were performed at 550 and $600{ }^{\circ} \mathrm{C}$ for varying stress at the National Institute for Materials Science in Japan (NIMS) with very high accuracy (NIMS, 1996) and seven creep curves were obtained in total. The specimen size was $6 \mathrm{~mm}$ in diameter and $30 \mathrm{~mm}$ in gauge length. The temperatures of both the specimen and test room were controlled within $\pm 2{ }^{\circ} \mathrm{C}$ and the minimum detected displacement was less than $5 \mu \mathrm{m}$. The creep rate was calculated using digital creep curves that were drawn from a set of time and displacement data and the practical detectable limit of the creep rate was below $1 \times 10^{-5} \mathrm{~h}^{-1}$.

\subsection{Analytical PROCedures and RESULTS}

3.2.1 Variations of $Q_{\mathrm{ex}}, V_{\mathrm{ex}}$, and $C_{\mathrm{ex}}$

Figure 1 shows the relation between linear stress and the logarithm of the minimum creep rate; we can confirm a linear relationship in the figure. This indicates that Equation 29 is satisfied for the MCR instead of the steady-state creep rate. According to an experimental rule that the time to rupture is inversely proportional to the MCR (Monkman \& Grant, 1956), an equation similar to Equation 29 may be obtained for the time to rupture. Therefore, the linear semi-logarithmic relationship for the time to rupture is also confirmed in Figure 1 as is explained previously (Larson \& Miller, 1952; Tamura et al., 1999; Tamura et al., 2003; Tamura et al., 2013; Tamura, 2015). 


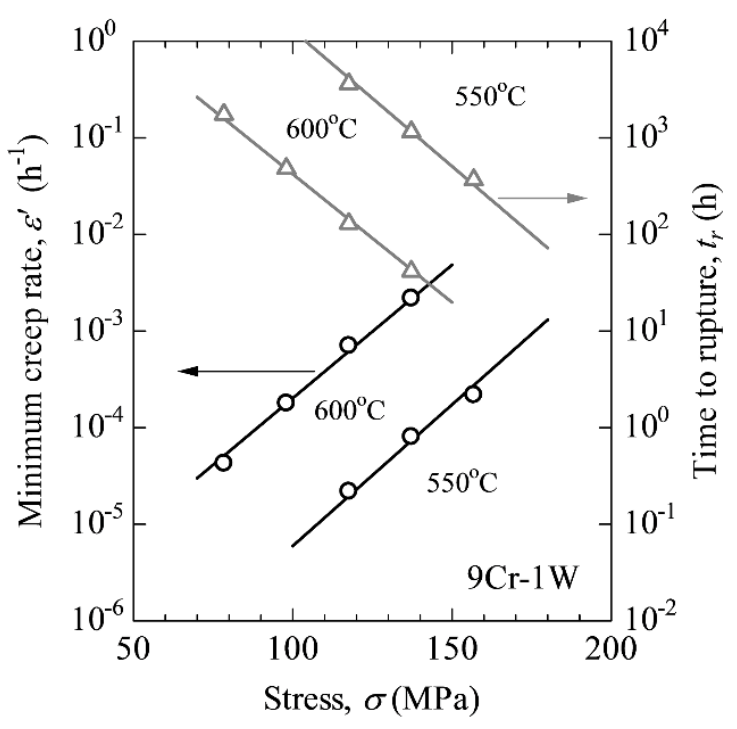

Figure 1. Minimum creep rate and time to rupture for $9 \mathrm{Cr}-1 \mathrm{~W}$ steel as functions of stress

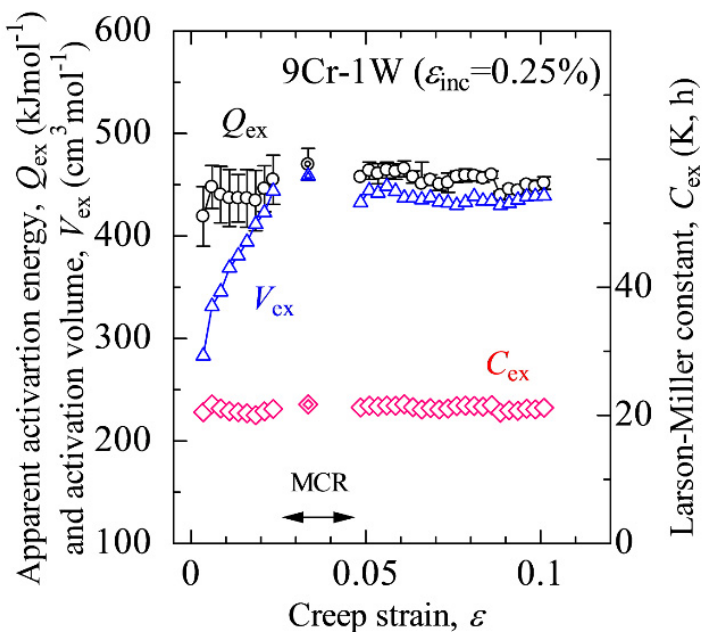

Figure 2. Variations in $Q_{\mathrm{ex}}, V_{\mathrm{ex}}$ and $C_{\mathrm{ex}}$ as functions of creep strain for $9 \mathrm{Cr}-1 \mathrm{~W}$ steel. For simplicity, the error bars are shown only for $Q_{\text {ex }}$. The double arrow indicates the existing range of strain for the minimum creep rate (MCR) of the original creep curves. The values $Q_{\mathrm{ex}}, V_{\mathrm{ex}}$, and $C_{\mathrm{ex}}$ for the MCR were obtained using Equation 35 and individual minimum-creep-rate data, and the results are plotted at a strain for the MCR of the synthesized strain rate versus strain curve, shown in Figure 9. Similar plots are presented in the following figures, but the explanation is omitted for brevity

\subsubsection{Determination of the actual domain size $\alpha d_{m}$ and correction term $\gamma$}

First, the change in the Gibbs free energy can be calculated according to Equation 37 assuming that $\gamma=0$ and using the values shown in Figure 2 for the average temperature $\left(578.6^{\circ} \mathrm{C}\right)$ and stress $(120.5 \mathrm{MPa})$. The value of $\phi$ that is needed to calculate the Gibbs free energy and that is related to the temperature dependence of the shear modulus in Equation 38 was calculated using Young's modulus and Poisson's ratio at high temperatures (ASME, 2013). We next obtained $\alpha d_{\mathrm{m}}(\gamma=0)$ using $\Delta G(\gamma=0)$ and Equation 42; the results are shown in Figure 3. In this calculation, $\kappa=1, v_{\mathrm{D}}=10^{13} \mathrm{~s}^{-1}$, and $b=2.5 \times 10^{-10} \mathrm{~m}$ were assumed, and the strain increment $\varepsilon_{\text {inc }}$ was the increase in strain between adjacent data points, or $0.25 \%$ as shown in the figure. 


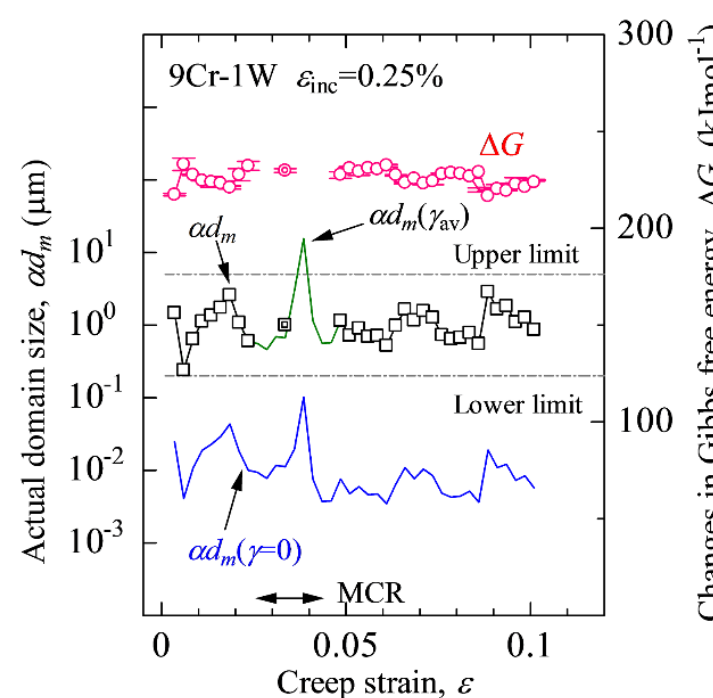

Figure 3. Actual domain size and changes in the Gibbs free energy as functions of creep strain for $9 \mathrm{Cr}-1 \mathrm{~W}$ steel

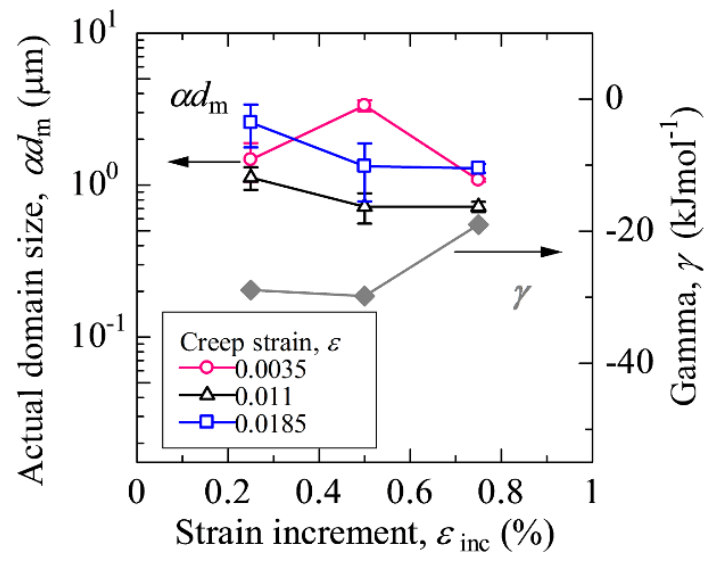

Figure 4. Variations in actual domain size, $\alpha d_{\mathrm{m}}$, and gamma, $\gamma$, as functions of the strain increment, $\varepsilon_{\text {inc }}$, for $9 \mathrm{Cr}-1 \mathrm{~W}$ steel

The correction term $\gamma$ for $\Delta G$ in Equation 37 could be neglected at low temperatures (Schoeck, 1980), but $\gamma$ may vary according to changes in microstructure and test conditions at high temperatures. It is reasonable, therefore, that the values of $\gamma$ are calculated for the transition and acceleration creep ranges separately, as follows. First, we chose the data set with $\alpha d_{\mathrm{m}}(\gamma=0)$, which satisfies the relationship $d_{\mathrm{l}} \leq \alpha d_{\mathrm{m}}(\gamma=0) \leq d_{\mathrm{u}}$. Next, if in the absence of these data as shown in Figure 3, we calculate both $\gamma\left(\alpha d_{\mathrm{m}}=d_{\mathrm{l}}\right)$ and $\gamma\left(\alpha d_{\mathrm{m}}=d_{\mathrm{u}}\right)$ for each data set using Equation 42. The average value of gamma is then denoted $\gamma_{\mathrm{av}}$. In Figure 3, in the case of $d_{1}=0.2 \mu \mathrm{m}$ and $d_{\mathrm{u}}=5 \mu \mathrm{m}$, the values of $\gamma_{\mathrm{av}}$ are -28.92 and $-35.71 \mathrm{kJmol}^{-1}$ for the transition creep range and the acceleration creep range, respectively. The mean value of $\gamma_{\mathrm{av}}$ for the transition and acceleration creep ranges (i.e., -32.32 $\mathrm{kJmol}^{-1}$ ) is used as the value of $\gamma_{\mathrm{av}}$ for the MCR.

Using Equation 42, we calculate the domain size for each $\gamma_{\mathrm{av}}$ and denote it $\alpha d_{\mathrm{m}}\left(\gamma_{\mathrm{av}}\right)$. The results are shown by the green line in Figure 3. Even in this state, when the data for $\alpha d_{\mathrm{m}}\left(\gamma_{\mathrm{av}}\right)$ do not satisfy $d_{\mathrm{l}} \leq \alpha d_{\mathrm{m}} \leq d_{\mathrm{u}}$, a value closer to $d_{1}$ or $d_{\mathrm{u}}$ was assigned to $\alpha d_{\mathrm{m}}$, as shown near the MCR range in the figure. The change in the Gibbs free energy when using the finally selected $\gamma$ is calculated and the results are shown in Figure 3 . In the figure error bars are shown for each data point of $\Delta G$, where $\Delta G$ values are calculated for the upper and lower values of $Q_{\mathrm{ex}}$ and $V_{\mathrm{ex}}$ shown in Figure 2 using Equation 37, though the values for $V_{\mathrm{ex}}$ are omitted for simplicity, and the range of the error bar is determined to be the difference between the values of $\Delta G$ for the upper and lower values of $Q_{\mathrm{ex}}$ and $V_{\mathrm{ex}}$. The variations in $\Delta G$ shown in the figure are very similar to those in $Q_{\mathrm{ex}}$; however, the values of $\Delta G$ are about half those of $Q_{\mathrm{ex}}$.

Figure 4 shows the variations in $\alpha d_{\mathrm{m}}$ and $\gamma$ for a given creep strain, $\varepsilon$, as functions of the strain increment, $\varepsilon_{\text {inc }}$. In Figure 4 error bars are shown for each $\alpha d_{\mathrm{m}}$ and are calculated using the same method described for $\Delta G$ in Figure 3, but using Equation 42. The values of $\alpha d_{\mathrm{m}}$ are selected as values satisfying Equation 43, as a matter of course, and the selected $\gamma$, which is independent of $\varepsilon$ in the transition creep range, tends to approach a certain value, approximately $-30 \mathrm{kJmol}^{-1}$, for $\varepsilon_{\text {inc }} \approx 0$. In any case, the correction term, $\gamma$, is not so large when compared with the values of $\Delta G$, as shown in Figure 3.

\subsubsection{Calculation of Dislocation Density and Factors Affecting the Density}

Dislocation densities can be easily calculated using both Equation 20 for a given $\varepsilon_{\text {inc }}$ and the finally decided actual domain size, $\alpha d_{\mathrm{m}}$. Figure 5 shows variations in the dislocation density at the average temperature and under average stress as a function of creep strain for a given strain increment, $\varepsilon_{\text {inc }}=0.25 \%$. The dislocation density has a peak at $0.6 \%$ strain and a valley at $2 \%$ in the transition creep range followed by fluctuations around $2 \times 10^{13} \mathrm{~m}^{-2}$ in accordance with creep strain in the acceleration creep range. It should be recalled that we use different values of $\gamma$ for the strain increment of $\varepsilon_{\text {inc }}=0.25 \%$ in the transition and acceleration ranges; i.e., -28.92 and $-35.71 \mathrm{kJmol}^{-1}$, respectively. If we apply the $\gamma$ value for the transition creep range to the whole range of creep, the calculated dislocation density is a little higher for the acceleration creep range. The data point 
of the MCR is shown by a double circle, because the accuracy of the calculation is not sufficiently near the MRC range and it may be reasonable to consider that the dislocation density near the MCR range varies from the end point of the transition creep range to the beginning point of the acceleration creep range through the MCR data point not along a solid polygonal blue line.

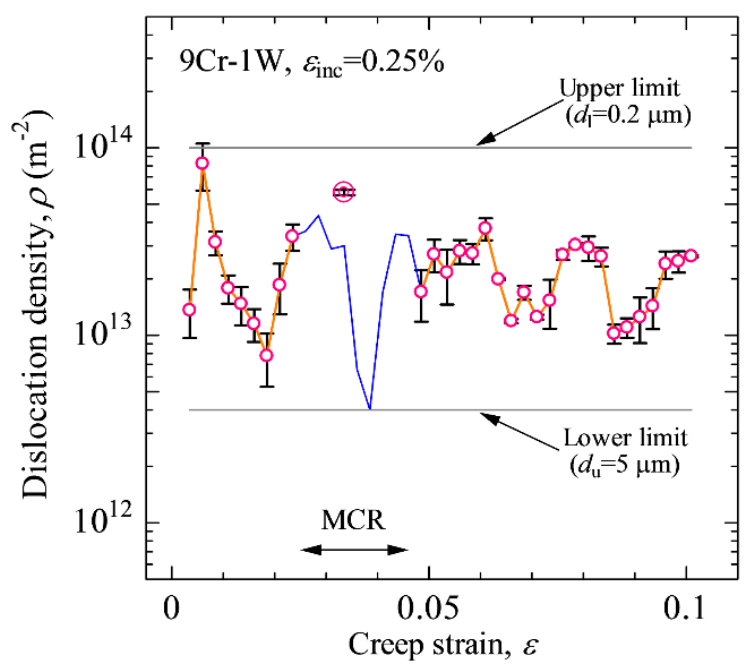

Figure 5. Calculated dislocation density with error bars for $9 \mathrm{Cr}-1 \mathrm{~W}$ steel

The calculated data points and the upper (for $d_{\mathrm{l}}=0.2 \mu \mathrm{m}$ ) and lower (for $d_{\mathrm{u}}=5 \mu \mathrm{m}$ ) limits for dislocation density are also drawn in Figure 5. It is natural that the estimated dislocation density (including the data point of the MCR) is between the upper and lower limits for dislocation density shown in the figure. However, the variations in the density shown in Figure 5 might appear irregular or scattered. Therefore, the error bars are shown for the data points in Figure 5. The error bars are calculated using the same method described for $\Delta G$ in Figure 3, but using Equation 40. It is found that the changes in dislocation density for a given creep strain within the scattering of $Q_{\mathrm{ex}}$ and $V_{\mathrm{ex}}$ (i.e., the ranges for error bars) are clearly smaller than the changes in dislocation density caused by creep strain. Consequently, it is understood that the fluctuation in dislocation density according to the progress of creep strain is not largely affected by the scattering of $Q_{\mathrm{ex}}$ and $V_{\mathrm{ex}}$.

Equation 20 indicates that the dislocation density directly depends on strain increment, and therefore, variations in the dislocation density as a function of creep strain for a given strain increment, $\varepsilon_{\text {inc }}=0.25 \%, 0.5 \%$, and $0.75 \%$ are shown in Figure 6. In Figure 6, the minimum dislocation density for each $\varepsilon_{\text {inc }}$ (i.e., $\rho_{\text {inc }}$ ) given in Equation 14 and the minimum dislocation density for total creep strain, $\rho_{\mathrm{c}}=\varepsilon / M b d_{0}$, are also drawn. These values are far lower than the calculated dislocation densities shown in Figure 6 and, of course, $\rho_{\text {inc }}<\rho_{\mathrm{c}}$. Although the values of $\beta=\rho_{\text {inc }} / \rho$ defined by Equation 19 depend on both $\varepsilon_{\text {inc }}$ and $\varepsilon$ as seen in Figure 6 , the ratio, $\beta$, ranges approximately from $10^{-3}$ to $10^{-4}$. Dislocations corresponding to the difference between the swept-out dislocation density, $\rho$, and $\rho_{\text {inc }}, \rho-\rho_{\text {inc }} \approx \rho$, for each $\varepsilon_{\text {inc }}$ should stay near the actual domain boundaries. It is noteworthy that most dislocations generated during the activated processes remain near grain boundaries and thus contribute to maintain the continuity of the body, support grain boundary sliding, and introduce recovery or nucleation for recrystallized grains, and only a small number of the generated dislocations produce detectable creep strain in polycrystalline material.

Given that the dislocation density is proportional to the strain increment, $\varepsilon_{\text {inc }}$, as shown by Equation 20 , the dislocation densities for $\varepsilon_{\text {inc }}=0.50 \%$ and $0.75 \%$ are larger than those for $\varepsilon_{\text {inc }}=0.25 \%$ as shown in Figure 6 . However, Figure 6 shows that fluctuation in dislocation density depending on creep strain is not affected largely by the strain increment, which indicates the fluctuation in dislocation density is intrinsic.

The dislocation density varies in inverse proportion to $\alpha d_{\mathrm{m}}$ for a given $\varepsilon_{\text {inc }}$ as indicated by Equation 20 and the values of $\alpha d_{\mathrm{m}}$ are determined by the upper and lower limits of the deformable domain size, $d_{\mathrm{u}}$ and $d_{\mathrm{l}}$. The dislocation densities are then recalculated for the different values of $d_{\mathrm{u}}$ and $d_{\mathrm{l}}$ from the values shown in Figures 5 and 6; i.e., $d_{\mathrm{u}}=5 \mu \mathrm{m}$ and $d_{\mathrm{l}}=0.2 \mu \mathrm{m}$. The results are shown in Figure 7. The figure reveals that the dislocation density decreases for larger values of $d_{\mathrm{u}}$ or $d_{\mathrm{l}}\left(d_{\mathrm{l}}=1 \mu \mathrm{m}, d_{\mathrm{u}}=5 \mu \mathrm{m}\right.$ and $d_{\mathrm{l}}=0.2 \mu \mathrm{m}, d_{\mathrm{u}}=$ 
$20 \mu \mathrm{m})$ and increases for a smaller value of $d_{\mathrm{u}}\left(d_{\mathrm{u}}=1 \mu \mathrm{m}\right)$. These simulations indicate that the dislocation density decreases when the deformable domain size increases and consequently the microstructure may become coarser with the progress of creep deformation. As a matter of course, comparing the calculated values of $\alpha d_{\mathrm{m}}$ with the microstructure of the crept specimens will be a topic of future work.

In summarizing the findings taken from Figures 5, 6, and 7, we note that the dislocation density of $9 \mathrm{Cr}-1 \mathrm{~W}$ steel defined by Orowan's equation and calculated using Equation 40 ranges approximately $10^{13}-10^{14} \mathrm{~m}^{-2}$ during creep; only a small number of dislocations calculated (approximately $10^{-3}-10^{-4}$ ) are swept out of a specimen and generate creep strain, and consequently, most dislocations are accumulated or annihilated near boundaries; and the dislocation density fluctuates clearly with an increase in the creep strain though the dislocation density is approximately $2 \times 10^{13} \mathrm{~m}^{-2}$ depending on the experimental error of $Q_{\mathrm{ex}}$ and $V_{\mathrm{ex}}, \varepsilon_{\mathrm{inc}}$, and the upper and lower limits of $\alpha d_{\mathrm{m}}$, i.e., the variations in dislocation density shown in Figures 5, 6, and 7 are considered to be intrinsic and reliable. Therefore, a critical issue to be discussed here is that the dislocation density fluctuates clearly with an increase in creep strain as shown in Figures 5, 6, and 7.

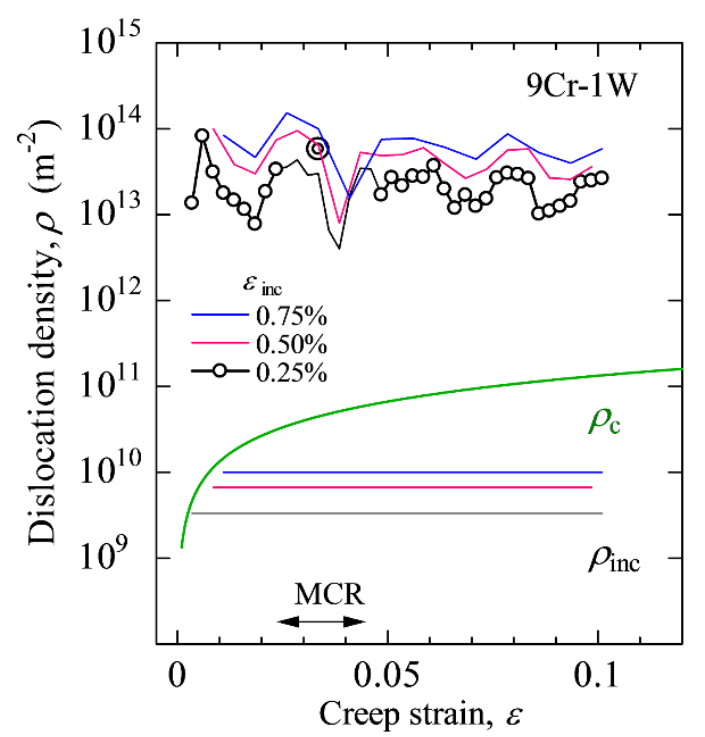

Figure 6. Calculated dislocation densities for $\varepsilon_{\text {inc }}=0.25 \%, 0.50 \%$, and $0.75 \%$, as functions of creep strain for 9Cr- $1 \mathrm{~W}$ steel. $\rho_{\mathrm{c}}$ and $\rho_{\text {inc }}$ are the minimum dislocation density for generating creep strain, $\varepsilon$, and each strain increment, $\varepsilon_{\text {inc }}$, respectively

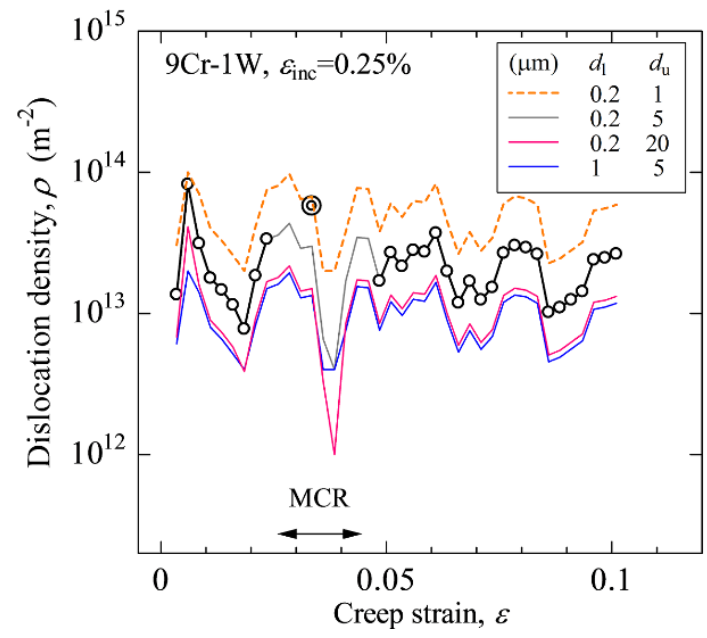

Figure 7. Calculated dislocation densities for $d_{\mathrm{u}}$ and $d_{1}$ listed in the figure, as functions of creep strain for $9 \mathrm{Cr}-$ $1 \mathrm{~W}$ steel 


\subsubsection{Calculated Dislocation Density and Comparison with Observations}

The calculated dislocation density shown in Figure 5 should not be compared directly with the observed dislocation density, because the annihilated dislocations are not taken into account in the calculated dislocation density, although we note that we cannot observe annihilated dislocations. Moreover, the initial dislocation density may affect the observed total dislocation density. The initial dislocation density of high-Cr martensitic heat-resistant steels for practical uses (e.g., steel types of T91, P91, and P92 registered by the American Society for Testing and Materials (ASTM)) ranges from 1 to $9 \times 10^{14} \mathrm{~m}^{-2}$ and the decrease in total dislocation density during long-term thermal exposure or a creep rupture test under very low stress is not so large (Spiradek et al., 1994; Sawada et al., 1997; Ennis \& Czyrska-Filemonowicz, 2003; Panait et al., 2010; Dudova, Plotnikova, Molodov, Belyyakov, \& Kaibyshev, 2012). However, in a creep-interrupted test or rupture test conducted within approximately $1000 \mathrm{~h}$, the total dislocation density of the high-Cr martensitic heat-resistant steels for practical uses readily decreases to approximately $1 \times 10^{13} \mathrm{~m}^{-2}$, depending on the test temperature and stress (Sawada et al., 1997; Dudova et al., 2012). Meanwhile, Hayakawa et al. (2007) reported that though the initial dislocation density of $1 \mathrm{Cr}-0.5 \mathrm{Mo}$ steel (ASTM A213/A213M-10 T12) observed employing TEM is approximately $10^{12} \mathrm{~m}^{-2}$, total dislocation density increases approximately $10^{13} \mathrm{~m}^{-2}$ within a very small strain and there is then nearly constant total dislocation density until rupture. Bazazi (2009) made TEM observations and reported that though the total dislocation density of X20CrMoV12 1 steel (Deutsch Industrie Normen 1.4922) remains around $5 \times 10^{13} \mathrm{~m}^{-2}$ in an un-deformed grip portion, which is about half the initial value (i.e., $1.2 \times 10^{14} \mathrm{~m}^{-2}$ ), even after rupture after approximately $110000 \mathrm{~h}$ at $550^{\circ} \mathrm{C}$ and $120 \mathrm{MPa}$, the total dislocation density in a gauge portion decreases to $1 \times 10^{13} \mathrm{~m}^{-2}$ after a creep interruption test at $0.5 \%$ strain (about $10000 \mathrm{~h}$ ) and then gradual decreases to $7 \times 10^{12} \mathrm{~m}^{-2}$ at rupture. These observations indicate that though the microstructure strongly depends on temperature, stress, and/or strain, the initial dislocation structure readily changes in response to very low creep strain and then gradually decreases during creep and has rather low density at rupture, being a "soft material" that does not contain strong hardening particles of $(\mathrm{Nb}, \mathrm{V})(\mathrm{C}, \mathrm{N})$ like $1 \mathrm{Cr}-0.5 \mathrm{Mo}$ and X20CrMoV12-1 steels.
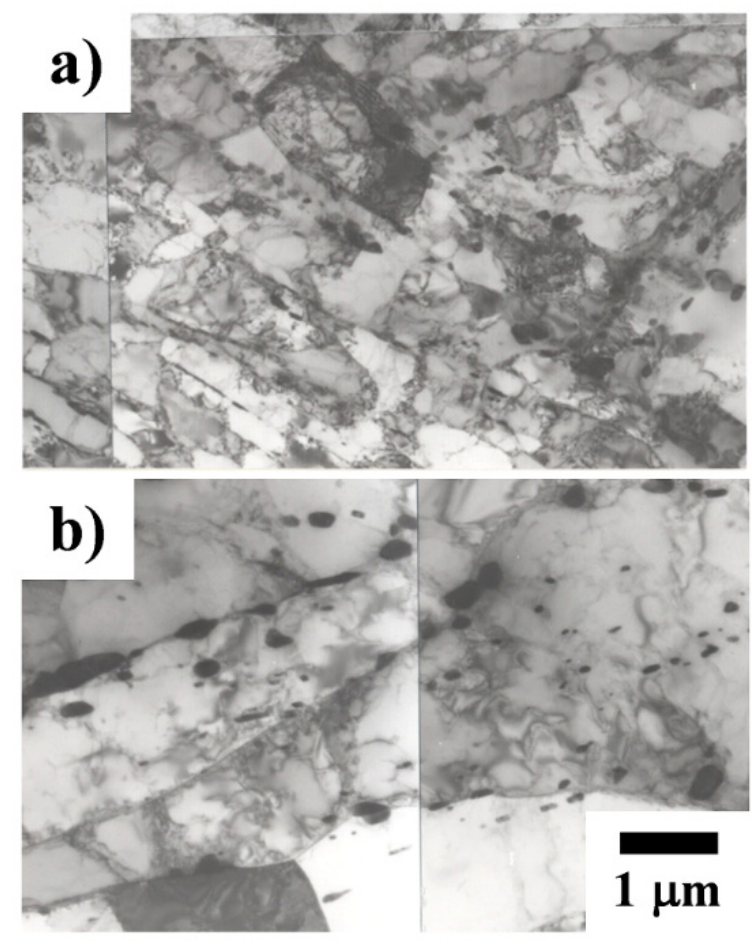

Figure 8. TEM images for $9 \mathrm{Cr}-1 \mathrm{~W}$ steel a) before creep testing and b) after rupture testing at $600{ }^{\circ} \mathrm{C}$ and $78 \mathrm{MPa}$ 
Although the dislocation density of $9 \mathrm{Cr}-1 \mathrm{~W}$ steel was not estimated employing TEM and we cannot provide TEM images for the creep interrupted specimen because there is no unused sample remaining, TEM images of 9Cr- $1 \mathrm{~W}$ steel before and after rupture testing at $600^{\circ} \mathrm{C}$ and $78 \mathrm{MPa}$ are presented in Figure 8. Abe (2003) confirmed through these TEM observations the high density of dislocations and fine $\mathrm{Cr}_{23} \mathrm{C}_{6}$ carbide particles present in the tempered lath martensitic structure before the creep test. Furthermore, after rupture, the total dislocation density decreased and the growth of lath martensite or the formation of subgrains and coarsening of Cr-carbides occurred owing to recovery. Abe et al. (1992) also reported that gradual decreases in hardness and mean width of lath martensite were observed using creep interrupted specimens in the acceleration creep range of a tempered martensitic steel of $9 \mathrm{Cr}-2 \mathrm{~W}$ steel similar to $9 \mathrm{Cr}-1 \mathrm{~W}$ steel. Neither $9 \mathrm{Cr}-1 \mathrm{~W}$ or $9 \mathrm{Cr}-2 \mathrm{~W}$ steel contain strong hardening particles $(\mathrm{Nb}, \mathrm{V})(\mathrm{C}, \mathrm{N})$ and the results of the TEM observations for $9 \mathrm{Cr}-\mathrm{W}$ steels mentioned above are similar to those for X20CrMoV12 1 steel (Bazazi, 2009). Therefore, 9Cr-1W steel can be categorized as a "soft material", where the effect of the initial dislocation structure disappears within a very small creep strain.

The observed dislocation densities correspond to the values of the generated dislocations for creep minus the annihilated dislocations plus the effect of the initial dislocation density. However, because $9 \mathrm{Cr}-1 \mathrm{~W}$ steel is categorized as a "soft material", we assume that the effect of the initial dislocation density can be ignored in comparing the calculated dislocation density with the observations. Moreover, if the annihilated dislocation density can be assumed to be not so large as compared with the total dislocation density generated, it is understood that the calculated dislocation density of approximately $10^{13}-10^{14} \mathrm{~m}^{-2}$ during creep shown in Figures 5, 6, and 7 is roughly in agreement with the total dislocation density of approximately $10^{13} \mathrm{~m}^{-2}$ observed for low alloy steel of a similar soft material. A strict comparison of the calculated values with the observations requires evaluation of $\alpha d_{\mathrm{m}}$, the annihilated dislocation density, and the strain increment. The strain increment of the specimen for the TEM observation corresponds to the interrupted total creep strain, i.e., several $\%$, and therefore, the calculated dislocation density for the TEM observation may be large as compared with the dislocation density shown in Figures 5, 6, and 7 (i.e., $10^{13}-10^{14} \mathrm{~m}^{-2}$ ). However, in that case, the number of annihilated dislocations may increase. In any case, if the results shown in Figures 5, 6, and 7 are accepted to be roughly reasonable, we must consider the meaning of the fluctuation in the dislocation density during creep.

Here, we also discuss briefly the mobile dislocation density. In steady-state creep, an increase in dislocation density within a certain interval (e.g., $\varepsilon_{\text {inc }}=0.25 \%$ ), $\rho$, is equal to the mobile dislocation density. However, most dislocations corresponding to $\rho$ stay near the boundaries and the minimum dislocation density for creep is defined as $\rho_{\mathrm{c}}=\varepsilon / M b d_{0}$ as mentioned above. Therefore, the mobile dislocation density in grains ranges between $\rho$ and $\rho_{\mathrm{c}}$. The mobile dislocation density observed employing TEM or the mobile dislocation density, $\rho_{\mathrm{m}}$, calculated from a stress change test indicates usually dislocations in grains. Therefore, we obtain the relation, $\rho>\rho_{\mathrm{m}}>\rho_{\mathrm{c}}$ and possibly $\rho_{\mathrm{m}} \approx \rho_{\mathrm{c}}$, because dislocations near the boundaries are not taken into account. We therefore obtain $\rho_{\mathrm{m}} \approx 5 \times 10^{10} \mathrm{~m}^{-2}$ for the creep strains of the MCR shown in Figure 5. Hayakawa et al. (2007) calculated mobile dislocation densities of carbon steel, low alloy steel, and $9 \mathrm{Cr}-1 \mathrm{MoVNb}$ steel (T91) by conducting a stress change test and reported that the mobile dislocation densities increase with a gradual increase in the creep strain and reached $1-3 \times 10^{11} \mathrm{~m}^{-2}$ at rupture, while the mobile dislocation density varies in the range $10^{10-11} \mathrm{~m}^{-2}$ at a very small strain depending on the alloy type and test conditions. Therefore, the estimated mobile dislocation density $\rho_{\mathrm{m}} \approx 5 \times 10^{10} \mathrm{~m}^{-2}$ for the MCR of $9 \mathrm{Cr}-1 \mathrm{~W}$ steel well agrees with the observed values for similar steels.

\section{Discussion}

\subsection{Rate-Controlling Variables during Creep}

An average creep rate can be calculated for the average temperature and stress using $Q_{\mathrm{ex}}, V_{\mathrm{ex}}$, and $C_{\mathrm{ex}}$ as shown in Figure 2. The average dislocation velocity is then easily calculated using Equation 1, the average creep rate, and the dislocation density shown in Figure 5. The results are shown in Figure 9 for $\varepsilon_{\text {inc }}=0.25 \%$ as a function of creep strain. Error bars of the average velocity are omitted for simplicity, because variations in the creep rate is very small, and therefore, it is estimated from Equation 1 that error bars of the average velocity should be the same as those of the dislocation density shown in Figure 5. The average velocity seems to vary inversely against the dislocation density and the variations in the velocity and density are larger and more like polygonal lines as compared with the variation in the creep rate. The velocity ranges approximately from $10^{-5}$ to $10^{-4} \mu \mathrm{ms}^{-1}$ and is rather low. This indicates that dislocations are barely observed employing high-resolution and highmagnification TEM. The apparent low velocity shown in Figure 9 is the result of averaging over all swept-out dislocations, most of which remain near the domain boundaries. 


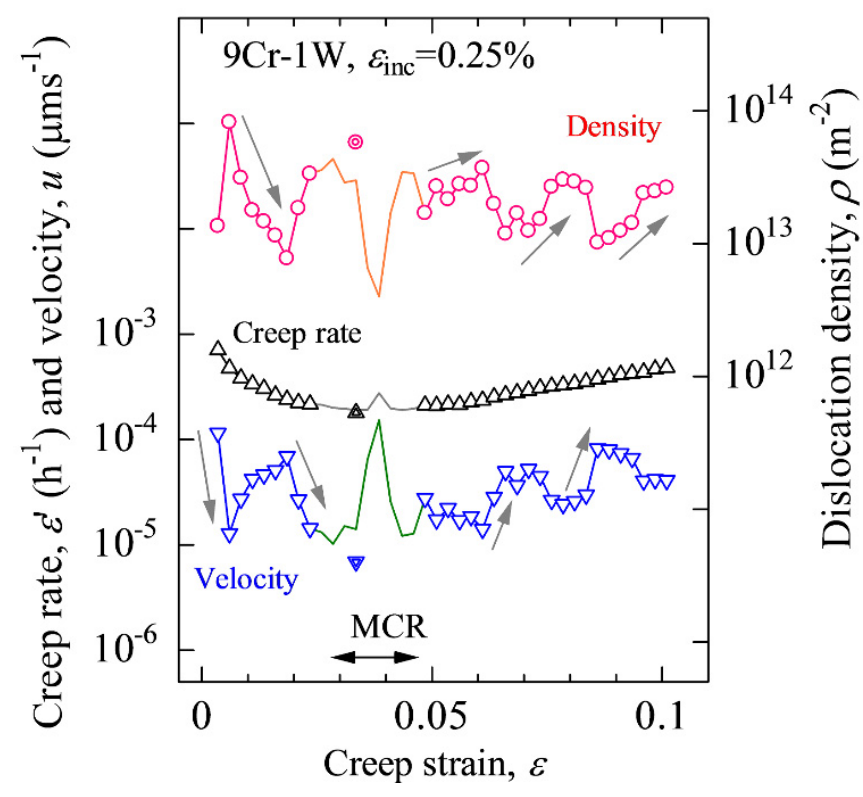

Figure 9. Dislocation density, creep rate, and average velocity as functions of creep strain for $9 \mathrm{Cr}-1 \mathrm{~W}$ steel. Rate controlling variables are schematically shown by arrows

Equation 1 indicates that, when the creep rate decreases, at least one of $\rho$ and $u$ should decrease with an increase in strain and the decreasing variables $\rho$ and/or $u$ are thus rate-controlling variables in the transition creep range, and in contrast, that when the creep rate increases in the acceleration creep range, at least one of $\rho$ and $u$ should increase with an increase in strain and the increasing variables $\rho$ and/or $u$ are thus rate-controlling variables. In Figure 9, the rate controlling variables are indicated by arrows schematically. The figure shows that "hardening" occurs when creep begins, which reduces the dislocation velocity, during which time the dislocation density increases in the opposite manner. Then, in the creep strain range between $0.6 \%$ and $2 \%$ (i.e., approximately 10 to $100 \mathrm{~h}$ ), the velocity increases gradually and the dislocation density decreases. In this creep strain range, the actual domain size, $\alpha d_{\mathrm{m}}$, also increases as shown in Figure 3, which indicates that "recovery" is initiated even in the transition creep range. In this stage, the decreasing dislocation density is a rate-controlling variable. Next, the creep velocity decreases again, which is followed by a region including the MCR point. Although the calculation accuracy for $\rho$ and $u$ is insufficient for the polygonal lines near the MCR range, the dislocation velocity may tend to decrease towards the MCR data point shown by an inverse double triangle. In the acceleration creep region, inversions from hardening to recovery and vice versa are frequently observed. The velocity increases slightly throughout the acceleration creep range and, in contrast, the dislocation density decreases, which corresponds to the macroscopic occurrence of recovery during the acceleration creep range. However, we observe a roughly slow increase in the dislocation density as shown by arrows three times, while there is a rapid and obvious increase in velocity twice as shown by arrows. This suggests that there is a "slow hardening period" even in the acceleration creep range. In any case, frequently observed increasing variables are rate-controlling variables in the acceleration creep range.

The initial decrease in the velocity may result from hardening due to the effect of instantaneous strain and the second decrease near $2 \%$ creep strain (at approximately $100 \mathrm{~h}$ ) may be related to the systematical rearrangement of texture due to the progress of recovery, because these changes are often observed according to the electron backscattering pattern during early tempering and the short-term creep of high-Cr martensitic steels (Sawada et al., 1997; Tamura et al., 2006a; Tamura, Nowell, Shinozuka, \& Esaka, 2006b), and 9Cr-1W steel does not precipitate anything other than preexisting $\mathrm{Cr}_{23} \mathrm{C}_{6}$ carbide during creep (Abe, 2003). Figure 9 surprisingly shows that recovery and subsequently hardening repeatedly occur and that recovery does not take place continuously, even in the acceleration creep. These phenomena have not yet been reported in the open literature and must be further studied in detail.

\subsection{Monitoring of Recovery}

All dislocations that are calculated as swept-out dislocations should be trapped and annihilated near the domain boundaries, except for dislocations swept out of the specimen. As long as a high density of dislocations remains near the boundaries, a certain creep strength will be maintained. Occasionally, accumulated dislocations may result in the formation of nuclei for the recovered zone, the growth of domains, or the formation of new sub-grains that 
lead to an increase in $\alpha d_{m}$ and/or the average velocity. This indicates the essential decrease in strength, but the observed creep rate in the transition creep range is reduced by the decrease in the dislocation density. In the acceleration creep range, there is another decrease followed by an increase in the dislocation density (or vice versa in the velocity), which indicates repeated occurrences of recovery and hardening, and finally, the material approaches rupture as seen in Figure 9.

In the above-mentioned situation, if we can detect the early inversion point from hardening to recovery even in the transition creep range and if other hardening processes such as precipitation hardening are contrived according to the metallurgical considerations, we can slow the recovery rate or delay the inversion point of the modified steel. Therefore, by monitoring the inversion of the dislocation density or the recovery rate represented by arrows in Figure 9 for the transition creep range, the finding of an early beginning of recovery allows for a prediction of an unexpected decrease in long-term creep strength. Of course, this is based on the idea that the early recovery may be a trigger for early rupture at a later time. Therefore, this correlation should be studied further. However, it must be useful to monitor the dislocation density in improving a material. This monitoring of a set of creep curves at near stress levels of the $10^{5}$-h rupture strength can be carried out nondestructively and is quicker than waiting for rupture to occur over a very long time. Creep tests should thus be conducted with high accuracy. In this case, determining the point of inversion from hardening to recovery during the transition creep range would be feasible. The analysis described above indicates that both the dislocation density and velocity can be evaluated as functions of the creep strain using creep data, fundamental Equations 1 and 8, and several serious assumptions, such as Equations 5 and 10 . Only one parameter (i.e., the value of $\gamma$ or the actual deformable domain size, $\alpha d_{\mathrm{m}}$, in Equation 42) is assumed on the basis of metallurgical considerations and the dislocation densities are calculated. In this study, the upper and lower limits of $\alpha d_{\mathrm{m}}$ were assumed to be constant throughout each transition and acceleration creep range, but it is also possible to treat these limits as variables during creep according to metallurgical investigations. However, the simple method shown in Figure 3 and thus Figures 5 and 9 is sufficient to qualitatively monitor the variations in the dislocation density during creep.

Figure 6 shows that the variations in dislocation density can be declared in more detail for a finer strain increment at low creep strain, though the frequency of calculations increases. Accordingly, the dislocation density is calculated at almost even intervals on a logarithmic scale and the results are shown in Figure 10 with those for the strain increments of $0.25 \%, 0.5 \%$, and $0.75 \%$. Here, we can reduce the number of calculations, and moreover, investigate in more detail especially at a small strain. Additionally, we can detect a sign of the initiation of early recovery even at almost even intervals on a logarithmic scale, because as seen in Figure 10 referring to Figure 5, we can reconfirm the change near $0.6 \%$ strain is correlated with the inversion shown in Figure 5. Creep strain in an early transition creep range of high-strength heat-resistant steel is generally very low as compared with that of $9 \mathrm{Cr}-1 \mathrm{~W}$ steel. Therefore, it is useful in the case of high-strength steel to calculate the dislocation density as a function of creep strain with almost even intervals on a logarithmic scale.

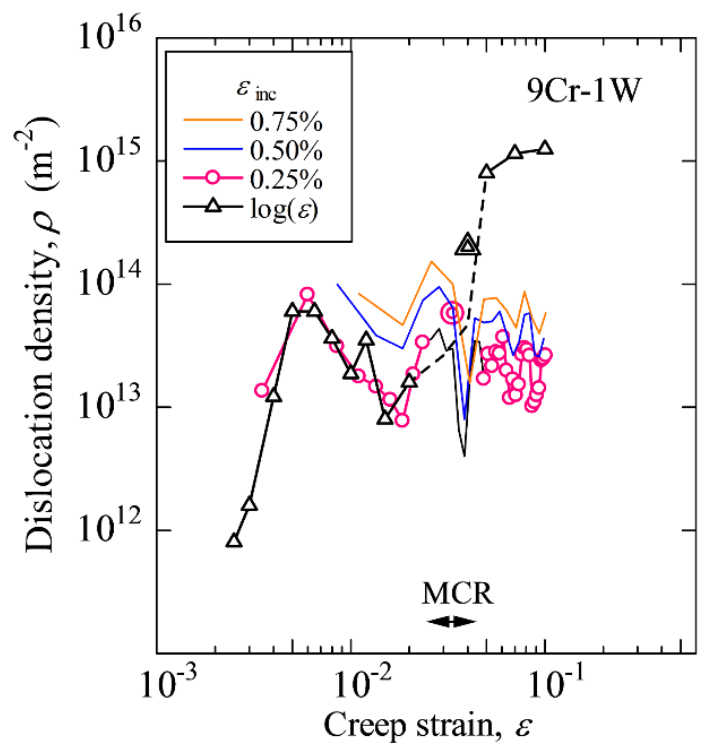

Figure 10. Variations in dislocation density as functions of creep strain at even intervals of $\varepsilon_{\text {inc }}$ and $\log \varepsilon_{\text {inc }}$ for $9 \mathrm{Cr}-1 \mathrm{~W}$ steel 
The inversion point near $0.6 \%$ creep strain confirmed in Figures 5, 6, 7, 9, and 10 is derived by analyzing only the creep curves. Therefore, it might be possible that another sign of early recovery can be detected by investigating directly the changes in creep rate in detail excluding heavy calculations, fuzzy assumptions, and an adjustable parameter, $\gamma$ or $\alpha d_{m}$, as mentioned above. However, the changes in creep rate are not so clear as shown in Figure 9 , and therefore, it is not so easy to extract a sign of early recovery from the creep curves. Even though changes in creep rate could be detected, the physical or metallurgical meaning of the change is unclear. Therefore, it is a practical approach to detect a sign for long-term degradation of creep strength within a short time by calculating the dislocation density during creep using Equation 30 and using creep curves obtained under the conditions near the stress levels of the $10^{5}$-h rupture strength, where the physical meanings of the variables are clear, though the assumptions adopted should be validated in future work.

After recognizing that the calculated dislocation density is reasonable and the physical meaning of each variable is clear, however, we can choose another easy method to detect a sign of the long-term degradation of creep strength. Figure 11 shows the correlation between the dislocation density and the apparent activation energy, $Q_{\mathrm{ex}}$. With an increase in creep strain, the data point for $\rho$ and $Q_{\mathrm{ex}}$ shifts from a solid red circle at the lower left along the solid line in the transition creep range, skips to a solid blue triangle at the upper left in the acceleration creep range via a double circle for the MCR, and again shifts along a solid line with open triangles, while $Q_{\text {ex }}$ increases or decreases in a manner similar to the change in dislocation density and a positive correlation holds. It is difficult to specify a dislocation model to calculate the value of $Q_{\mathrm{ex}}$ for martensitic steel, but the values can be easily obtained from creep curves as a function of creep strain as shown in Figure 2. It is thus possible to judge that early recovery may occur when $Q_{\mathrm{ex}}$ begins to decrease by monitoring the changes in $Q_{\mathrm{ex}}$ as a function of creep strain calculated from creep curves under the $10^{5}$-h rupture strength levels (with a minimum of three creep tests). According to the judgement of the occurrence of the early recovery, we can start the modification of the developed material within an early time.

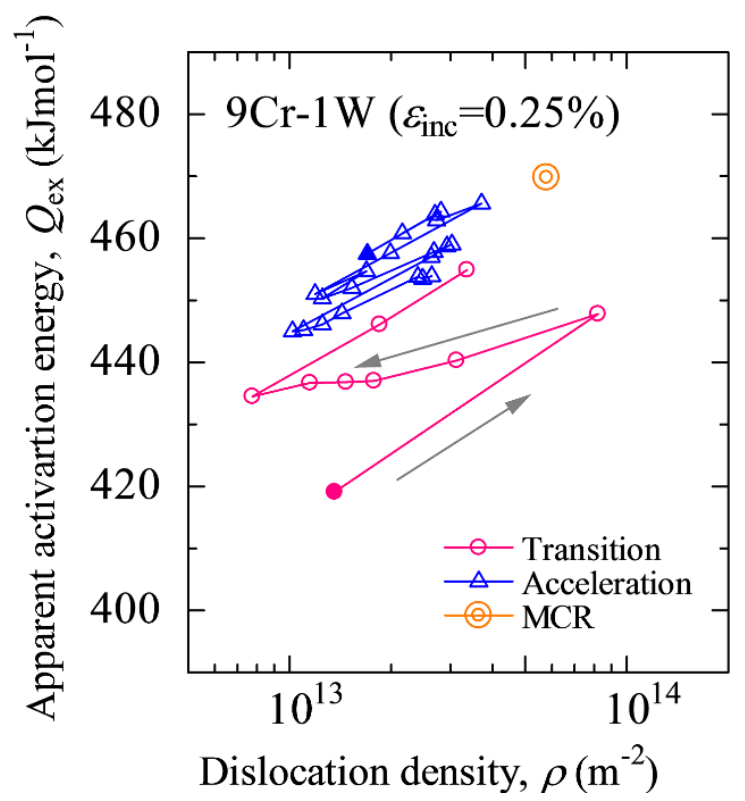

Figure 11. Correlation between dislocation density and experimentally obtained apparent activation energy for $9 \mathrm{Cr}-1 \mathrm{~W}$ steel

The logarithm of the creep rate has been plotted as a function of the logarithm of the stress. In this case, we can easily obtain the apparent activation enthalpy, $\Delta H_{\mathrm{ex}}$, using Equation 32 as a function of creep strain. A diagram similar to Figure 11 is obtained for the relation between $\rho$ and $\Delta H_{\mathrm{ex}}$. Therefore, monitoring $\Delta H_{\mathrm{ex}}$ is also effective. We can detect a sign of the long-term degradation of creep strength by monitoring $Q_{\mathrm{ex}}$ or $\Delta H_{\mathrm{ex}}$; however, it should be remembered that the inversion from an increase to a decrease in $Q_{\mathrm{ex}}$ or $\Delta H_{\mathrm{ex}}$ with an increase in the creep strain is caused by the change in the dislocation density, which corresponds to the early initiation of recovery. 


\subsection{Meaning of the Calculation Equation for the Dislocation Density}

Equation 40 is used to calculate the dislocation density that generates a strain increment, $\varepsilon_{\text {inc }}$, through an adjustable parameter, $\gamma$, which is determined through $\alpha d_{\mathrm{m}}, d_{\mathrm{u}}$, and $d_{1}$ using Equations 42 and 43 (see Figure 3). The calculation uses the values of $Q_{\mathrm{ex}}$ and $V_{\mathrm{ex}}$, which are obtained from the creep rate at a specific strain using Equation 35 . We can thus calculate the dislocation density nondestructively for a given strain. The dislocation densities calculated for $9 \mathrm{Cr}-1 \mathrm{~W}$ steel are similar to the total dislocation density observed for a similar heat-resistant steel employing TEM. The definition of the dislocation density used in this study is different from the total dislocation density observed; however, this can be explained by referring to the literature and the assumptions made as mentioned above. Although the dislocation density depends on not only $\alpha d_{\mathrm{m}}, d_{\mathrm{u}}$, and $d_{\mathrm{l}}$ but also the strain increment, $\varepsilon_{\text {inc }}$, if these variables are assumed to be constant during creep deformation, the dislocation density calculated varies appreciably as shown in Figures 5, 6, and 7.

A critical problem in introducing Equation 40 for polycrystalline may be whether correlating Equation 1 with Equation 2 or Equation 8 is valid. There is no problem applying Orowan's equation (Equation 1) to the deformable domain in polycrystalline that is considered to be a single crystal, because Equation 1 is a basic equation for plastic deformation of a single crystal and we assume the MCR to be the rate of steady-state flow, and therefore, the dislocation density defined in this study is considered to be the mobile dislocation density in Equation 1. However, Equations 2 and 8 are derived for a model in which the motion of a single dislocation overcomes thermally dispersive obstacles of the same quality in a single crystal. When we consider the motion of many dislocations based on Equation 8, these dislocations should not elastically interact with each other, but this situation is practically improbable. If dislocations glide with random timing in a crystal and elastically interact with each other, we cannot define $\Delta g$ in Equation 25. However, when we apply Equation 2 or 8 to polycrystalline, we should consider the motion of many dislocations, though such models have not yet been developed. We therefore treated the creep phenomenon as a whole process.

The essence of Equation 8 is that the potential energy required for a dislocation to overcome an obstacle is reduced by $\sigma v$. The activation distance included in $\sigma v$ should theoretically be $\Delta x \approx 0.5 b$ in a crystalline material as shown in Equation 9. However, in polycrystalline, since we cannot specify a dislocation model, the unknown variable $X_{\mathrm{a}}$ was introduced as the activation distance as described by Equation 10. When Equation 10 is solved satisfying the relation between the observed strain rate and the applied stress, we obtain $X_{\mathrm{a}}=\left(\alpha d_{\mathrm{m}}\right) / \alpha=d_{\mathrm{m}}$ as shown in Equation 24. We can estimate $\alpha \approx 3.8 \times 10^{-5}$ for the MCR and $\varepsilon_{i n c}=0.25 \%$ using Equation 22 and the value of $V_{\mathrm{ex}}$ shown in Figure 2 , and assuming $V \approx V_{\mathrm{ex}}$, and using the MCR, we obtain $X_{a}=\left(\alpha d_{\mathrm{m}}\right) / \alpha \approx$ $1 / 3.8 \times 10^{-5} \mu \mathrm{m} \approx 1 \times 10^{8} \mathrm{~b}$. This suggests that the activation distance in polycrystalline, $X_{\mathrm{a}}$, may be considerably larger than the theoretical value of $\Delta x \approx 0.5 b$ for a single dislocation and equivalent obstacles in a single-crystal model. In contrast, assuming $X_{\mathrm{a}} \approx b$ and $\alpha d_{\mathrm{m}} \approx 1 \mu \mathrm{m}$, which corresponds to $\rho=2 \times 10^{13} \mathrm{~m}^{-2}$, we obtain from Equation $24 \alpha=4000$. This estimation contradicts Equation 18; $\alpha \equiv \varepsilon_{\text {inc }} / \varepsilon_{\mathrm{a}}, 0<\alpha<1$. It may thus be concluded that applying the thermally activated equation of Kauzmann type, Equation 8, to polycrystalline is theoretically incorrect.

However, it has been well confirmed that an approximate exponential equation of Equation 8 can be widely applied to arranging time-to-rupture or MCR data of many kinds of heat-resistant steels, Ni base alloys, and solders that are obtained under widely spread test conditions (Kanter in a Larson-Miller's paper, 1952; Tamura, Esaka, \& Shinozuka, 1999; Tamura, Esaka, \& Shinozuka, 2003). Therefore, though the contradiction concerning the activation distance, $X_{\mathrm{a}}$, mentioned above is not yet solved, Equation 40 for calculating the dislocation density, which is based on Equations 1 and 8 and an adjustable parameter $\gamma$ (i.e., $\alpha d_{\mathrm{m}}$ ) is valid for practical use. This contradiction will be solved in future work, if the random motion of many dislocations can be modeled and $X_{\mathrm{a}}$ can be solved. However, the aim of the present work is not solving this problem but rather detecting a sign of the long-term degradation of the rupture strength of martensitic steel within a short time using Equation 40 via an adjustable parameter, $\gamma$; i.e., $\alpha d_{\mathrm{m}}$.

If Equation 40 is reasonable or acceptable, a sign of early recovery in the transition creep range that may be a trigger for the long-term degradation of creep strength of martensitic steel can be extracted, whatever the absolute value of the dislocation density. When the sign of early degradation is detected nondestructively by analyzing creep curves obtained under the conditions around the estimated $10^{5}$-h strength levels after development of a new material, we can start to take counter measures such as micro-alloying, modification of the chemical composition, and/or heat treatment within an early time. Though there is a more simple and practical way of monitoring the apparent activation energy, $Q_{\mathrm{ex}}$, mentioned above, rather than monitoring the estimated dislocation density, it is essential to understand the physical meaning of the variables to calculate the dislocation density using Equation 40 . 


\section{Conclusions}

1) An equation for the dislocation density is introduced by making several assumptions and using one variable, $\gamma$, as an adjustable parameter. The value of $\gamma$ is determined by selecting the actual deformable domain size according to metallurgical considerations. Using the equation and a set of creep curves, the dislocation density in polycrystalline heat-resistant steel during creep can be estimated as a function of creep strain nondestructively.

2) The estimated dislocation densities for $9 \mathrm{Cr}-1 \mathrm{~W}$ steel are approximately within the range of total dislocation densities measured employing TEM for similar heat-resistant steels.

3) The dislocation density of $9 \mathrm{Cr}-1 \mathrm{~W}$ steel increases or decreases repeatedly during creep. The point of conversion from increasing to decreasing dislocation density within the transition creep range probably indicates the occurrence of early recovery, which suggests an unexpected decrease in long-term rupture strength.

\section{References}

Abe, F., Nakazawa, S., Araki, H., \& Noda, T. (1992). The role of microstructure instability on creep behavior of a martensitic 9Cr-2W steel. Metallurgical Transactions A, 23, 469-477. http://dx.doi.org/10.1007/BF02801164

Abe, F. (2003). Effect of quenching, tempering, and cold rolling on creep deformation behavior of a tempered martensitic 9Cr-1W steel. Metallurgical and Materials Transactions A, 34, 913-925. http://dx.doi.org/10. 1007/s11661-003-0222-x

Abe, F. (2005). Effect of fine precipitation and subsequent coarsening of $\mathrm{Fe}_{2} \mathrm{~W}$ laves phase on the creep deformation behavior of tempered martensitic $9 \mathrm{Cr}-\mathrm{W}$ steels. Metallurgical and Materials Transactions A, 36, 321-332. http://dx.doi.org/10.1007/s11661-005-0305-y

Abe, F., Tabuchi, M., Tsukamoto, S., \& Shirane, T. (2010). Microstructure evaluation in HAZ and suppression of Type IV fracture in advanced ferritic power plant steel. International Journal of Pressure Vessels and Piping, 87, 598-604. http://dx.doi.org/10.1016/j.ijpvp.2010.08.005

Abe, F. (2011, March). Influence of transient creep on acceleration creep of mod. 9Cr-1Mo steel, Paper presented at the $161^{\text {st }}$ ISIJ Meeting at Tokyo City University, Tokyo. Abstract shown in CAMP-ISIJ, 2011, 24, 340. No online documment.

Andrade, E. N. da C. (1910). On the viscous flow in metals, and allied phenomena. Proceeding of Royal Society of London, Section A, 84, 1-12. http://dx.doi.org/10.1098/rspa.1910.0050

ASME Bolier and Pressure Vessel Code Sec. II Part D, Tables TM-1 and PRD. (2013). NY: ASME.

Bazazi, A. A. (2009). Evolution of microstructure during long-term creep of a tempered martensite ferrtic steel (Doctoral dissertation). Ruhr-Universität Bochum. Retieved from http://www-brs.ub.ruhr-uni-bochum.de/ netahtml/HSS/Diss/Aghajani

Briggs, J. Z., \& Pakker, T. D. (1965). The super 12\% Cr steels. Ann Arbor, MI: Climax Molybdenum Company of Michigan. http://dx.doi.org/10.1002/maco.19660170738

Cottrell A. H., \& Aytekin, V. (1947). Andrade's creep law and the flow of zinc crystals. Nature, 160, 328-239. http://dx.doi.org/10.1038/160328a0

Cottrell A. H., \& V. Aytekin, V. (1950). The flow of zinc under constant stress. Journal of the Institute of Metals, 77, 389-422. No online documment.

Cottrell, A. H. (1965). Theory of Crystal Dislocations, Schenectady. NY: Gordon and Breach Sci. Pub. No online documment.

Cottrell, A. H. (1997). Logarithmic and Andrade creep. Philosophycal Magazine Letters, 75, 301-308. http://dx.doi.org/10.1080/095008397179552

Dickenson, J. H. S. (1922). Some experiments on the flow of steels at a low red heat, with a note on the scaling of heated steels, part I. Journal of the Iron and Steel Institute, 106, JISI, 103-154. No online documment.

Dudova, N., Plotnikova, A., Molodov, A., Belyyakov, A., \& Kaibyshev, R. (2012). Structural changes of tempered martensitic $9 \% \mathrm{Cr}-2 \% \mathrm{~W}-3 \% \mathrm{Co}$ steel during creep at $650{ }^{\circ} \mathrm{C}$. Materials Science and Engineering: A, 534, 632-639. http://dx.doi.org/10.1016/j.msea.2011.12020

Dushman, S., Dunbar L.W., \& Huthsteiner, H. (1944). Creep of metals. Journal of Applied Physics, 15, 108-124. http://dx.doi.org/10.1063/1.1707401 
Eisenlohr, P., Blum, W., \& Milicka, K. (2009). Dislocation glide velocity in creep of Mg alloys derived from dip tests. Materials Science and Engineering: A, 510-511, 393-397. http://dx.doi.org/10.1016/j.msea.2008. 04.120

Elarbi, Y. M. (2008). Weldability of high Cr and $1 \%$ tungsten alloyed creep resistant martensitic steel (Dissertation of Ph.D). Budapest University of Technology and Economics, Budapest, Hungary. Retrieved from http://www.omikk.bme.hu/collections/phd/Gepeszmernoki_Kar/2009/Yousef_Mosbah_Elarbi/ertekezes.pdf

Ennis, P. J., \& Czyrska-Filemonowicz, A. (2003). Recent advances in creep-resistant steels for power plant applications. Sadhana, 28(3-4), 709-730. http://dx.doi.org/10.1007/BF02706455

Esherby, J. D. (1956). The continuum theory of lattice defects. In F. Seitz and D. Turnbull (Eds.) Solid State Physics: Advances in Research and Applications, 3, 79-145. NY: Academic Press Inc.

Eyring, H. (1936). Viscosity, plasticity, and diffusion as examples of absolute reaction rates. The Journal of Chemical Physics, 4, 283-291. http://dx.doi.org/10.1063/1.1749836

Gibbs, G. B. (1964). The thermodynamics of creep deformation. physica status solidi, 5, 693-696. http://dx.doi.org/10.1002/pssb.19640050323

Gibbs, G. B. (1965). The thermodynamics of thermally-activated dislocation glide. physica status solidi, 10, 507512. http://dx.doi.org/10.1002/pssb.2220100212

Gibbs, G. B. (1969). Thermodynamic analysis of dislocation glide controlled by dispersed local obstacles. Materials Science and Engineering, 4, 313-328. http://dx.doi.org/10.1016/0025-5416(69)90026-3

Hayakawa, H., Nakashima, S., Kusumoto, J., Kanaya, A., Terada, D., Yoshida F., \& Nakashima, H. (2007). Evaluation of creep deformation mechanism of heat-resistant steel by stress change test. In Proc. CREEP8 Eighth International Conference on Creep and Fatigue at Elevated Temperatures July 22-26 San Antonio, TX CREEP2007-26501 (pp. 1-10). Warrendale, PA.: ASME. http://dx.doi.org/10.1115/CREEP2007-26501

Ishida, Y., Cheng, C.-Y., \& Dorn, J. E. (1966). Creep mechanisms of alpha iron. Transactions of the metallurgical Society of AIME, 236, 964-971. Retrieved from https://publications.lbl.gov/islanddora/object/ir\%3A140194

Kauzmann, H. (1941). Flow of solid metals from the standpoint of the chemical-rate theory. Transactions of the American Institute of Mining and Metallurgical Engineers, 143, 57-83.

Kimura, K., Sawada, K., Kubo, K., \& Kushima, H. (2004). Influence of stress on degradation and life prediction of high temperature ferritic steels. ASME/JSME 2004 Pressure Vessels and Piping Conference, Experience With Creep-Strength Enhanced Ferritic Steels and New and Emerging Computational Methods, PVP-476, Paper No. PVP2004-2566, 11-18. http://dx.doi.org/10.1115/PVP2004-2566

Klueh, R. (2004). Elevated-temperature ferritic and martensitic steels and their application to future nuclear reactors. ORNL/TM-2004/176, 1-66. http://dx.doi.org/10.1179/174328005X41140

Kushima, H, Kimura, K., \& Abe, F. (1999). Degradation of mod. 9Cr-1Mo steel during long-term creep deformation. Tetsu-to-Hagane, 85, 841-847. Retrieved from https://www.jstage.jst.go.jp/article/tetsutohagane1955/85/11/85 _11_841/_article

Larson F. R., \& Miller, J. (1952). A time-temperature relationship for rupture and creep stresses. Transactions of the American Institute of Mining and Metallurgical Engineers, 74,765-775. No online documment.

Maruyama, K., Nakamura, J., \& Yoshimi, K. (2014). Change in temperature dependence of creep rupture life of high Cr ferritic steel. Tetsu-to-Hagane, 100, 414-420. Retrieved from https://www.jstage.jst.go.jp/article/ tetsutohagane/100/3/100_100_TETSU-2013-107/_article

Masuyama, F. (2007). Creep rupture life and design factors for high-strength ferritic steels. International Journal of Pressure Vessel and Piping, 84, 53-61. http://dx.doi.org/10.1016/j.ijpvp.2006.09.006

Monkman F. C., \& Grant, N. J. (1956). An empirical relationship between rupture life and minimum creep rate in creep-rupture tests. Proceedings of American Society for Testing and Materials, 56, 593-620. Retrieved from http://www.astm.org/DIGITAL_LIBRARY/STP/MMR/PAGES/PRO1956-56.htm

Mura, T., \& Mori, T. (1976). Micromechanics-Dislocation and Inclusions (in Japanese), Tokyo: Baihukan. ASIN: B000JA16HW.

Naoi, H., Miura, H., Ohgami, M., Morimoto, H., Tanaka, T., Yazaki, Y., \& Fujita, T. (1995). NF616 pipe production and properties and welding consumable development. In E. Metcalfe (Ed.), New Steels for 
Advanced Plant up to $620^{\circ} \mathrm{C}$, The EPRI/National Power Conference (pp. 8-28). 11 May, The Society of Chemical Industry, London, UK. No online documment.

NIMS: Testing Plan and Testing Procedures for NIMS Creep Data Sheets Project, TD No.10. (1996). Tokyo: the National Institute for Materials Science in Japan [NIMS]. Retrieved from http://www.nims.go.jp/mits/ english/creep_lst._e.htm

Norton, F. H. (1929). The Creep of Steel at High Temperatures. NY: McGraw-Hill Book Co. Retrieved from https://archive.org/details/creepofsteelathi00nort

Oikawa, H. (1982). Lattice self-diffusion in solid iron: A critical review. Technology Reports of the Tohoku University, 47, 67-77. Retrieved from http://www.worldcat.org/title/technology-reports-of-the-tohokuuniversity/oclc/2451160

Oikawa, H. (1983). Lattice diffusion of substitutional elements in iron and iron-base solid solutions. Technology Reports of the Tohoku University, 48, 7-77. Retrieved from http://www.worldcat.org/title/technology reports-of-the-tohoku-university/oclc/2451160

Orlova, A. (1988). On the mobile dislocation density in creep. Czechoslovak Journal of Physics B, 38, 502-504. http://link.springer.com/article/10.1007\%2FBF01597464 DOI: 10.1007/BF01597464

Orlova, A. (1992). Two concepts of mobile dislocation density in creep at high temperatures. Materials Science and Engineering: A, 151, 153-160. http://dx.doi.org/10.1016/0921-5093(92)90203-D

Orowan, E. (1940). Problems of plastic gliding. Proceedings of the Physical Society, 52, 8-22. http://dx.doi.org/10. 1088/0959-5309/52/1/303

Panait, C. G., Zielinska-Lipiec, A., Kosiel, T., Czyrska-Filemonowics, A., Gourgues-Lorenzon, A.-F., \& Bendick, W. (2010). Evolution of dislocation density, size of subgrains and MX-type precipitates in a P91 steel during creep and during thermal ageing at $600{ }^{\circ} \mathrm{C}$ for more than $100000 \mathrm{~h}$. Materials Science and Engineering: A, 527, 4062-4069. http://dx.doi.org/10.1016/j.msea.2010.03.010

Piccolo, B. L., Martin J. L., \& Bonneville, J. (2000). Experimental study of mobile dislocation densities and velocities through transient mechanical tests. In I.M. Robertson, D.H. Lassila, B. Devincre, \& R. Phillips (Eds.), Mat. Res. Soc. Symp. Proc. Vol. 578 Multiscale Phenomena in Materials-Experiments and Modeling (pp. 21-25). Wallendale, PA.: Mat. Res. Soc. http://dx.doi.org/10.1557/PROC-578-21

Prager, M. (1995). Development of the MPC omega method for life assessment in the creep range. Journal of Pressure Vessel Technology, 117, 95-103. http://dx.doi.org/10.1115/1.2842111

Sawada, K., Maruyama, K., Komine R., \& Nagae, Y. (1997). Microstructural changes during creep and life assessment of mod. 9Cr-1Mo steel. Tetsu-to-Hagane, 83, 466-471. Retrieved from http://www.jstage.jst.go.jp/article/tetsutohagane1955/83/7/83_7_466/_article

Schäublin, R., Spätig P., \& Victoria, M. (1998). Microstructure assessment of the low activation ferritic/martensitic steel F82H. Journal of Nuclear Materials, 258-263, 1178-1182. http://dx.doi.org/10.1016/S00223115(98)00182-2

Schoeck, G. (1957). Theory of creep. In Creep and Recovery: a seminar on creep and recovery of metals held during the 38th National Metal Congress and Exposition, Cleveland, October 6 to 12, 1956, (pp. 199-226). Cleveland, OH: American Society for Metals. Book ID: BA18218756.

Schoeck, G., (1965). The activation energy of dislocation movement. physica status solidi, 8, 499-507. http://dx.doi.org/10.1002/pssb.19650080209

Schoeck, G. (1980), Thermodynamics and thermal activation of dislocations. In F.R.N. Nabarro (Ed.) Dislocations in Solids volume 3 Moving Dislocations (pp. 63-159). Amsterdam: North-Holland Pub. Co. http://dx.doi.org/10.1002/crat.19800151012

Seeger, A. (1957). The mechanism of glide and work hardening in face-centered cubic and hexagonal close-packed metals in dislocations and mechanical properties of crystals, In J. C. Fisher, W. G. Johnston, R. Thomson and T. Vreeland, Jr. (Eds.), Dislocations and Mechanical Properties of Crystals (pp.243-329). Schenectady, NY: General Electric Co. Retieved from https://archive.org/details/dislocationsandm032791mbp

Sherby, O. D., Orr R. L., \& Dorn, J. E. (1953). Creep Correlations of Metals at Elevated Temperatures in $25^{\text {th }}$ Techn. Rpt. Sr. 22 Issue 25 N7-onr-295 (1-44). Berkeley, CA: University of California. Retrieved from http://www.dtic.mil/dtic/tr/fulltext/u2/005978.pdf 
Sikka, V. K., Ward C. T., \& Thomas K. C. (1983). Modified 9 Cr-1Mo steel-an improved alloy for steam generator application in A.K. Khara (Ed.), Ferritic Steel for High Temperature Applications: Proceedings of an ASM International Conference on Production, Fabrication, Properties, and Application of Ferritic Steels for HighTemperature Applications (pp. 65-83). Warren, Pennsylvania, 6-8 October 1981 ASM, Metals Park, OH.

Spiradek, K., R. Bauer R., \& Zeiler, G., (1994). Microstructural changes during the creep deformation of $9 \% \mathrm{Cr}$ steel. In D. Coutsouradis, J. H. Davidson, J. Ewald, P. Greenfield, T. Khan, M. Malik, D. B. Meadowcroft, V. Regis, R. B. Scarlin, F. Schubert, D. V. Thornton (Eds.), Materials for Advanced Power Engineering, Part I: Proceedings of a Conference held in Liège (pp. 251-262). Belgium, 3-6 October 1994, Kluwer Academic Publishers, Amsterdam, the Netherlands. Retieved from www.springer.com/us/book/9780792330769

Sugino, Y., Ukai, S., Leng, B., Oono, N., Hayashi, S., Kaito, T., \& Ohtsuka, S. (2012). Grain boundary related deformation in ODS ferritic steel during creep test. Materials Transactions, 53, 1753-1757. http://dx.doi.org/ 10.2320/matertrans.M2012143

Sully, A. H. (1949). Metallic Creep and Creep Resistant Alloys, London, UK: Butterworths Scientific Publications. Retieved from http://www.amazon.co.uk/books/dp/B000QAD1IW, ASIN: B000QAD1IW

Tamura, M., Esaka, H., \& Shinozuka, K. (1999). Stress and temperature dependence of time to rupture of heat resisting steels. ISIJ International, 39, 380-387. http://dx.doi.org/10.2355/isijinternational.39.380

Tamura, M., Esaka, H., \& Shinozuka K. (2003). Applicability of an exponential law in creep of metals. Materials Transactions, 44, 118-126. Retrieved from https://www.jim.or.jp/journal/e/44/01/118.html

Tamura, M., Haruguchi, Y., Yamashita, M., Nagaoka, Y., Ohinata, K., Ohnishi, K., Itoh, E., Ito, H., Shinozuka, K., \& Esaka, H. (2006a). Tempering behavior of $9 \% \mathrm{Cr}-1 \% \mathrm{Mo}-0.2 \% \mathrm{~V}$ steel. ISIJ International, 46, 16931702. http://doi.org/10.2355/isijinternational.46.1693

Tamura, M., Nowell, M. M., Shinozuka, K., \& Esaka, H. (2006b). Creep behavior of double tempered 8\%Cr2\%WVTa martensitic steel. Materials Transactions, 47, 1332-1340. Retrieved from http://www.jim.or.jp/journal/e/47/05/1332.html

Tamura, M., Abe, F., Shiba, K., Sakasegawa, H., \& Tanigawa, H. (2013). Larson-Miller constant of heat-resistant steel. Metallurgical and Materials Transactions A, 44. http://dx.doi.org/2645-2661.10.1007/s11661-013 1631-0

Tamura, M. (2015). Method of estimating the long-term rupture strength of $11 \mathrm{Cr}-2 \mathrm{~W}-0.4 \mathrm{Mo}-1 \mathrm{Cu}-\mathrm{Nb}-\mathrm{V}$ steel. Metallurgical and Materials Transactions A, 46, 1958-1972. http://dx.doi.org/10.1007/s11661-015-2784-9

Taylor, G. I. (1934). A theory of the plasticity of crystals. Zeitschrift für Kristallographie, 89, 375-385. http://dx.doi.org/10.1524/zkri.1934.89.1.375

Yoshinaga, H. (1977). What is the internal stress during deformation of metals? Bulletin of the Japan Institute of Metals, 16, 197-203. Retrieved from https://www.jstage.jst.go.jp/article/materia1962/16/4/16_4_197/_pdf

Zener, C. (1951). Theory of $D_{\mathrm{o}}$ for atomic diffusion in metals. Journal of Applied Physics, 22, 372-375. http://dx.doi.10.1063/1.1699967

Zener, C. (1952). Theory of diffusion. In W. Schockley, J. H. Hollomon, R. Maurer (Eds.), Imperfections in nearly Perfect Crystals (pp. 289-314). NY: John Wiley \& Sons Inc. Retrieved from http://www.amazon.com/ Imperfections-Nearly-Perfect-Crystals-Shockley/dp/B000JF240A

\section{Copyrights}

Copyright for this article is retained by the author(s), with first publication rights granted to the journal.

This is an open-access article distributed under the terms and conditions of the Creative Commons Attribution license (http://creativecommons.org/licenses/by/3.0/). 